\title{
Relations between Cortical and Thalamic Cellular Events during Transition from Sleep Patterns to Paroxysmal Activity
}

\author{
M. Steriade and D. Contreras \\ Laboratoire de Neurophysiologie, Faculté de Médecine, Université Laval, Quebec, Canada G1K 7P4
}

We investigated in anesthetized cats the progressive development from EEG-synchronized sleep patterns to lowfrequency $(<15 \mathrm{~Hz})$ paroxysmal activities, most of them consisting of epileptic-like seizures with spike-wave (SW) complexes at 2-4 $\mathrm{Hz}$. We used multisite extra- and intracellular recordings of neocortical, reticular thalamic (RE), and thalamocortical (TC) neurons, including dual impalements of cortical and TC cells.

A subsample $(40 \%)$ of TC cells discharged spike bursts at $2-4 \mathrm{~Hz}$, in close time relation with the spiky, depth-negative field components of $\mathrm{SW}$ seizures in related neocortical areas. Full synchronization among TC cells that were resonant with the cortical seizure activity was progressively reached toward the end of the $\mathrm{SW}$ paroxysm. The remaining TC cells $(60 \%)$ were inhibited during the cortical SW seizures. We show that the duration and amplitude of hyperpolarization in TC cells paralleled the extent of cortical EEG paroxysm. Dual intracellular recordings of cortical and TC neurons demonstrate that during the cortical SW seizure, consisting of a tonic depolarization with superimposed paroxysmal spike bursts, the simultaneously recorded TC neurons displayed a tonic hyperpolarization associated with repetitive IPSPs, closely time related with cortical cell bursts. The inhibition of TC cells was presumably mediated by GABAergic RE thalamic neurons. Indeed, simultaneously recorded RE and TC neurons during the cortical SW paroxysm showed that cortical and RE cell excitation was accompanied by corresponding IPSPs in TC cells.

We emphasize the progressive development from sleep patterns to some forms of epileptic-like activities. We propose that the inhibitory processes found in a significant number of TC cells during cortical SW seizures may contribute to the loss of consciousness, due to obliteration of synaptic transmission through the thalamus.

IKey words: sleep oscillations, seizures, spike-wave discharges, cortex, thalamus, intracellular recordings, hyperpolarizations, EEG]

This study shows that paroxysmal events in corticothalamic systems progressively develop from sleep patterns and leads to the proposal that at least some forms of seizures cmerge without

\footnotetext{
Received Apr. 13, 1994; revised June 22, 1994; accepted July 1, 1994.

This work was supported by the Medical Research Council of Canada (Grant MT-3689). We thank G. Oakson for analysis software, and P. Giguère and D. Drolet for technical assistance. D.C. is a doctoral student, partially supported by a fellowship from the Savoy Foundation.

Correspondence should be addressed to Professor Dr. M. Steriade at the above address.

Copyright (C) 1995 Society for Neuroscience $0270-6474 / 95 / 150623-20 \$ 05.00 / 0$
}

apparent discontinuity from normally synchronized brain electrical activities. The idea that self-sustained afterdischarges are gradually generated from incremental responses was previously advanced by investigating field potentials in amygdalohippocampal circuits (Steriade, 1964). In that study, responses to repetitive stimuli progressively increased in amplitude and changed their waveforms until being nearly identical to potentials of the self-sustained afterdischarge. Similar aspects were reported at the level of corticothalamic systems. Indeed, cortical stimulation elicited augmenting responses in thalamic neurons that were progressively followed by self-sustained spike bursts during the intervals free of stimuli, with patterns and frequencies that were similar to those of evoked responses (see Fig. 18 in Steriade and Llinás, 1988). Such a pattern could eventually lead to epileptic-like activity in target thalamic neurons, with spikeand-wave (SW) complexes at a frequency of $2-4 \mathrm{~Hz}$, as in the absence seizures (Steriade et al., 1976). As well, rhythmic thalamic stimulation within the frequency of $\approx 10 \mathrm{~Hz}$, mimicking sleep spindles, was followed by self-sustained activity of the SW type in cortical neurons (Steriade and Yossif, 1974). It is now known that absence epilepsy of experimental animals and humans preferentially occurs during drowsiness or early stages of EEG-synchronized sleep accompanied by spindle oscillations (Steriade, 1974; Kellaway, 1985). As well, in the penicillin epilepsy model (Prince and Farrell, 1963), spindle oscillations may develop into bilaterally synchronous SW complexes at $2-4 \mathrm{~Hz}$ (Gloor and Fariello, 1988; Gloor et al., 1990).

During the past decade, the knowledge of mechanisms underlying some forms of epilepsy was facilitated by progress toward the understanding of cellular substrates of three major sleep rhythms: spindles $(7-14 \mathrm{~Hz}), \delta(1-4 \mathrm{~Hz})$, and slow $(<1$ $\mathrm{Hz}$ ) oscillations.

Spindles, the epitome of EEG synchronization at sleep onset, arise in the thalamus. The reticular thalamic (RE) GABAergic nucleus plays a cardinal role in the genesis and widespread synchronization of spindles in thalamocortical (TC) systems. Indeed, lesions of RE nucleus are followed by abolition of spindle rhythmicity in target TC systems (Steriade et al., 1985), and spindles occur as rhythmic field potentials and related spike bursts from neurons in the deafferented rostral pole of RE nuclcus (Stcriade et al., 1987). This result was at the basis of the hypothesis that RE nucleus generates spindles. The RE nucleus is a conditional pacemaker, as spindles may be initiated by excitatory inputs from the cerebral cortex or dorsal thalamus (Steriade et al., 1972; Waszak, 1974; Contreras et al., 1993; von Krosigk et al., 1993). The crucial role of RE nucleus in spindle synchronization throughout TC systems was postulated because of the widespread dorsal thalamic projections of RE nucleus (Jones, 1985), especially those arising in the rostral pole (Ster- 
iade et al., 1984), and because there is little cross talk between dorsal thalamic nuclei (Jones, 1985; Steriade et al., 1990). Since SW seizures may develop from spindles, it was hypothesized that any pharmacological manipulation that would decrease the inhibitory efficacy of RE neurons upon TC cells would also decrease the incidence of epileptic SW discharges (Steriade, 1990). This idea is supported by experimental data (see Discussion).

More recently, two other slcep oscillations have becn analyzed at the intracellular level. The $\delta$ rhythm appears in TC neurons at a membrane potential $\left(V_{m}\right)$ more negative than spindles (Steriade et al., 1991; Nuñez et al., 1992). By contrast to spindles, which arise through synaptic interactions in thalamic networks, clock-like stereotyped $\delta$ oscillations are generated in TC cells by an interplay between two of their voltage-gated currents (McCormick and Pape, 1990; Leresche et al., 1991; Soltesz et al., 1991). The very frequency of $\delta$ potentials suggests that, at high levels of thalamic synchronization following corticothalamic volleys (Steriade et al., 1991), this oscillation may take the form of SW discharges. As to the cortically generated slow rhythm at $<1 \mathrm{~Hz}$ (Steriade et al., 1993a), it has the virtue of grouping the two other sleep rhythms, spindles and $\delta$, within sequences recurring periodically, every 2-5 sec (Steriade et al., 1993b,c).

In the preceding paper (Contreras and Steriade, 1994) we described the phase relations between the depolarizing and hyperpolarizing phases of cortical, RE thalamic, and TC neurons during the slow and spindle oscillations. In the present study, we analyze the progressive transition from normal neuronal synchrony during sleep patterns to paroxysmal episodes of cellular synchronization. Our data, resulting from multisite extraand intracellular recordings, including simultaneous impalements of cortical and dorsal thalamic neurons, point to the leading role of cortical neurons in the genesis of paroxysms with frequencies below $15 \mathrm{~Hz}$ (among them typical SW discharges at $2-4 \mathrm{~Hz}$ ) and reveal the unexpected feature of sustained hyperpolarizations of TC neurons during SW cortical seizures.

\section{Materials and Methods}

Experiments were conducted on adult cats, anesthetized with urethane $(1.8 \mathrm{gm} / \mathrm{kg}$, i.p. $)$, or ketamine and xylazine $(10-15 \mathrm{mg} / \mathrm{kg}$ and $2-3 \mathrm{mg} /$ $\mathrm{kg}$, i.m.). The tissues to be incised and pressure points were previously infiltrated with lidocaine. The animals were paralyzed with gallamine triethiodide and artificially ventilated by monitoring the end-tidal $\mathrm{CO}_{2}$ concentration at $3.5-3.8 \%$. A permanent sleep-like state, as ascertained by continuous recording of the EEG, was maintained by administering additional doses of anesthetics during experiments. Rectal temperature $\left(37-39^{\circ}\right)$ and heartbeat were monitored. The stability of recordings was ensured by bilateral pneumothorax, cisternal drainage, hip suspension, and by filling the hole made in the calvarium to permit the passage of micropipettes with $4 \%$ agar dissolved in saline.

Recording and stimulation. The cortical EEG was recorded through coaxial electrodes whose tips were inserted in deep cortical layers while the rings were placed at the cortical surface or outer part of layer 1 ; through the extracellular microelectrodes that served for recordings of action potentials in the cerebral cortex and thalamus; as well as through screws into the calvarium. In addition, the electrothalamogram (EThG) was bipolarly recorded through electrodes inserted into various nuclei that also served for stimulation purposes.

Multisite simultaneous recordings were made intra- and extracellularly in various cortical areas and thalamic nuclei. In the cortex, we recorded from motor pericruciate areas 4 and 6, somatosensory areas $3 \mathrm{~b}$ and 1 and 2 in the coronal gyrus, and associational areas 5 and 7 in the anterior suprasylvian gyrus. In the thalamus, we recorded from the rostral pole and lateral districts of the RE nuclear complex; as well as from ventrolateral (VL), ventroposterior (VP), lateroposterior (LP), and intralaminar centrolateral (CL) nuclei. These nuclei are anatomically related to the above cortical areas (Jones, 1985). The recording techniques are the same as described in the previous paper (Contreras and Steriade, 1994).

At the end of the experiments, the animals received a lethal dose of sodium pentobarbital. The location of recording and stimulation electrodes was verified on frontal $80 \mu \mathrm{m}$ sections stained with thionin.

\section{Results}

Data base

More than 500 neurons were recorded intra- and extracellularly in various cortical areas, RE nucleus, and dorsal thalamic nuclei (see Contreras and Steriade, 1994). Of those, 124 neurons were entrained in paroxysmal episodes recurring periodically, that is, epochs of highly increased EEG wave amplitudes and neuronal synchronization that could be easily distinguished from the background activity, displaying electrographic features resembling seizure activity and being often followed by postictal depression. Many episodes included typical SW complexes at 2$4 \mathrm{~Hz}$, while other paroxysms consisted of mixed frequencies at 2-4 Hz and 10-15 Hz. Among the 124 neurons reaching paroxysmal states, 45 were recorded from cortical areas 4 and 6 , $3 \mathrm{~b}$ and 1 and 2, 5 and 7 ( 31 intra- and 14 extracellularly); 36 from the rostrolateral and peri-VP districts of RE nucleus (eight intra- and 28 extracellularly); and 43 from VL, VP, LP, and CL thalamic nuclei (24 intra- and 19 extracellularly). All intracellularly recorded neurons retained for analyses had a $V_{m}$ more negative than $-55 \mathrm{mV}$ and overshooting action potentials. Different criteria for identification of regular spiking and intrinsically bursting cortical neurons, $\mathrm{RE}$ neurons with prolonged spike bursts having acceleration-deceleration patterns (see Fig. 2A), and TC cells are provided in the preceding paper.

\section{Slowly recurring paroxysmal synchronization episodes in the cerebral cortex and their reflection in the thalamus}

Under urethane or ketamine and xylazine anesthesia, neocortical neurons recorded from a variety of sensory, association, and motor areas displayed a slow rhythm $(<1 \mathrm{~Hz})$, consisting of prolonged depolarizations, interrupted by long-lasting hyperpolarizations. While the slow cortical oscillation prevailed at $0.3-0.5 \mathrm{~Hz}$ under urethane, its frequency increased to $0.6-$ $0.9 \mathrm{~Hz}$ when ketamine was administered (see Steriade et al., 1993a). We found the same difference in the present experiments.

In 18 of 62 animals, the slow EEG rhythm developed into grouped, long-lasting $(\approx 15-25 \mathrm{sec})$ episodes, repeating cyclically every $\approx 30-45 \mathrm{sec}$, and consisting of waves whose frequencies progressively declined, from $10-15 \mathrm{~Hz}$ to $1-4 \mathrm{~Hz}$. Those EEG episodes took the aspect of paroxysmal synchronizations, as their onset and end could be quite clearly recognized from the background activity (Fig. 1). We recorded 34 cortical neurons from pericruciate areas 4 and 6 and anterior suprasylvian areas 5 and 7, and 58 thalamic neurons from RE, CL, LP, and VL nuclei, whose activities were closely related to the devclopment and time course of paroxysmal synchronizations. The salient findings are as follows.

(1) Using DC recordings at different depths in the cortex, we were able to distinguish various phases within the paroxysmal synchronizations (Fig. $1 A, B$ ). Those episodes started hesitantly, with depth-negative slow EEG waves of progressively increasing amplitudes during a period of $\approx 5-8 \mathrm{sec}$, thereafter developing into distinct negative waves at $10-15 \mathrm{~Hz}$. The spiky pattern of 


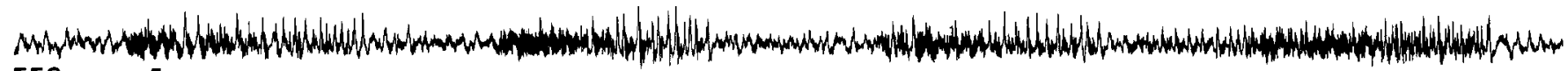
EEG area 5

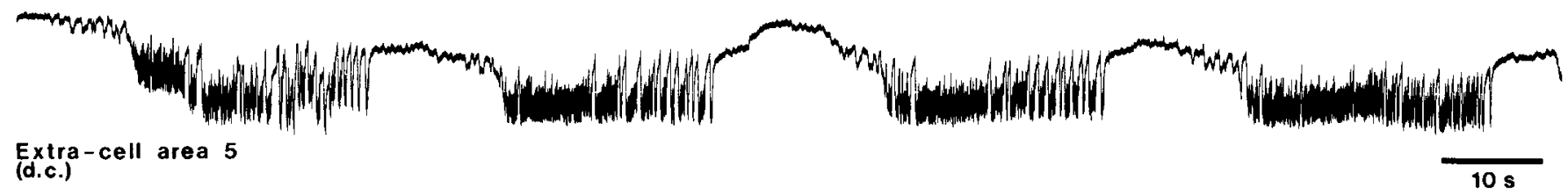

B EEG area 5

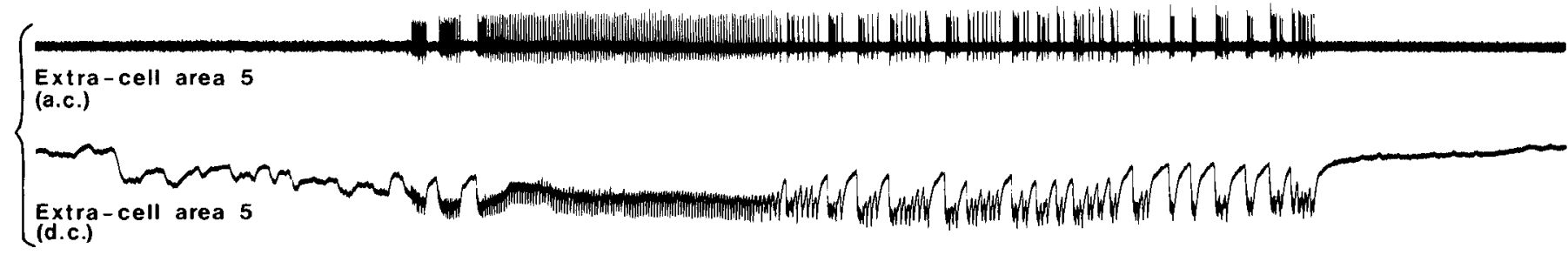

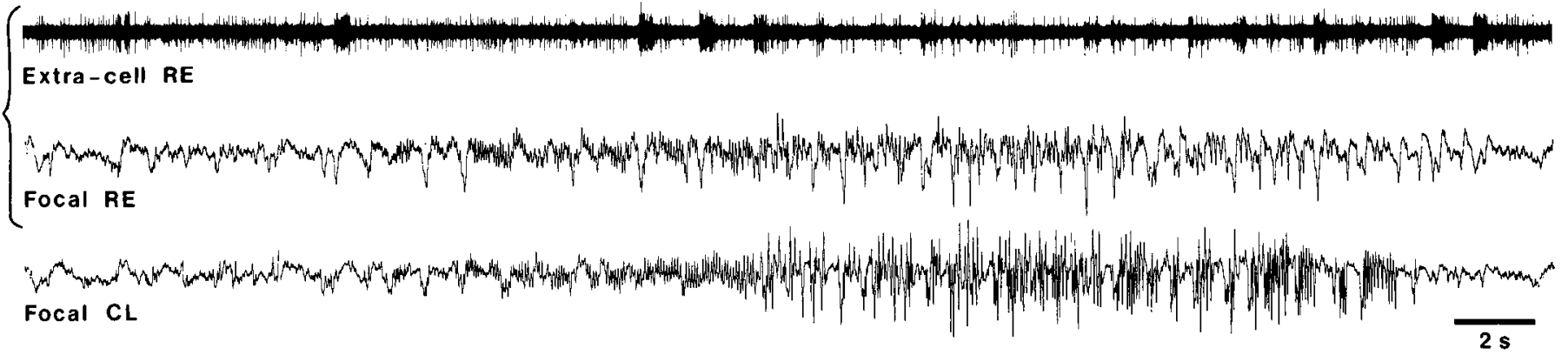

C

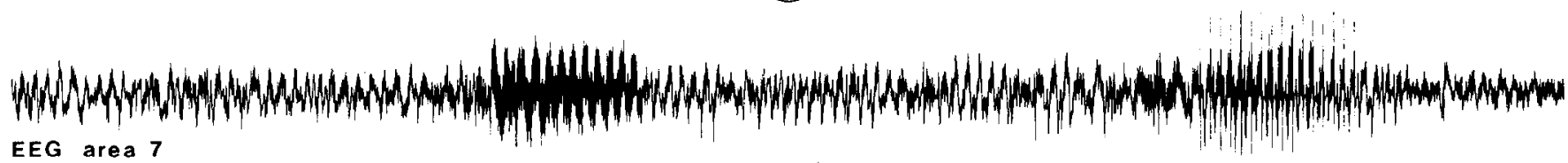

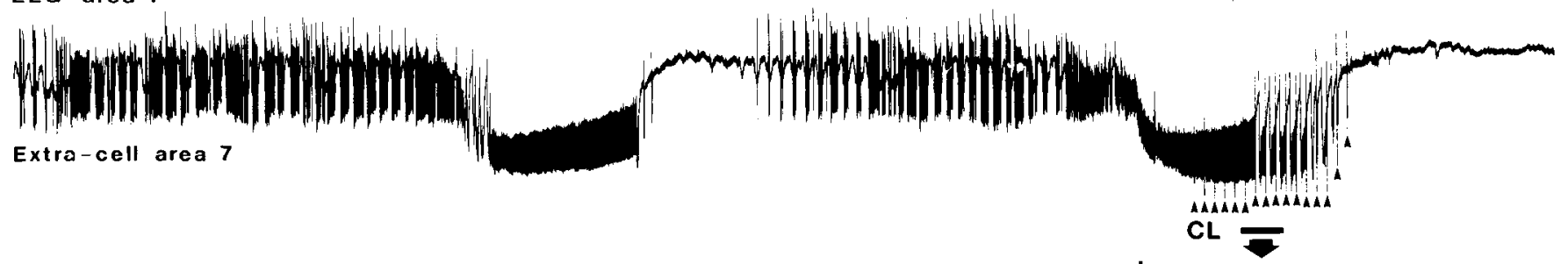

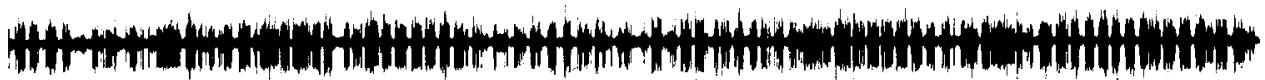

Extra-cell RE

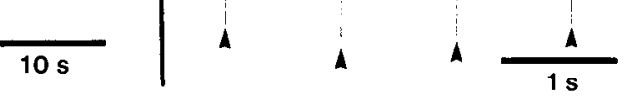

Figure 1. Cyclic paroxysmal synchronization episodes in parietal association cortex. $A-C$, Three different groups of simultaneous cortical and thalamic recordings. $A$, Four cycles of long-lasting $(\approx 20 \mathrm{sec})$ episodes repeating every $\approx 40 \mathrm{sec}$, each consisting of waves with a frequency of $10-$ $15 \mathrm{~Hz}$, eventually slowing to $1-3 \mathrm{~Hz}$. Surface EEG and depth-recorded $(0.8 \mathrm{~mm})$ d.c. activity in area 5 . $B$, Similar paroxysmal episode illustrated by simultaneous recording of surface EEG, a.c. and d.c. recording of area 5 cell (depth $1.2 \mathrm{~mm}$ ), RE thalamic neuron and focal waves (field potentials) recorded by the same microelectrode, and focal waves in rostral intralaminar CL thalamic nucleus. The paroxysm started with $12 \mathrm{~Hz}$ activity and ended at $3 \mathrm{~Hz}$. Note, in d.c. recording, that the episode was initiated by depth-negative waves in the cortex, with progressively increased amplitudes. $C, \mathrm{CL}$ thalamic stimulation is effective in inhibiting the paroxysmal oscillation $(12 \mathrm{~Hz})$ in the cortex. Suppression of cortical $12 \mathrm{~Hz}$ waves lasted for $\approx 0.3 \mathrm{sec}$ and was accompanied by a depth-positive field potential. Horizontal bar marks the epoch expanded below. In this and following figures, the positivity in all recordings (including field potentials and extracellular spikes) is upward. 

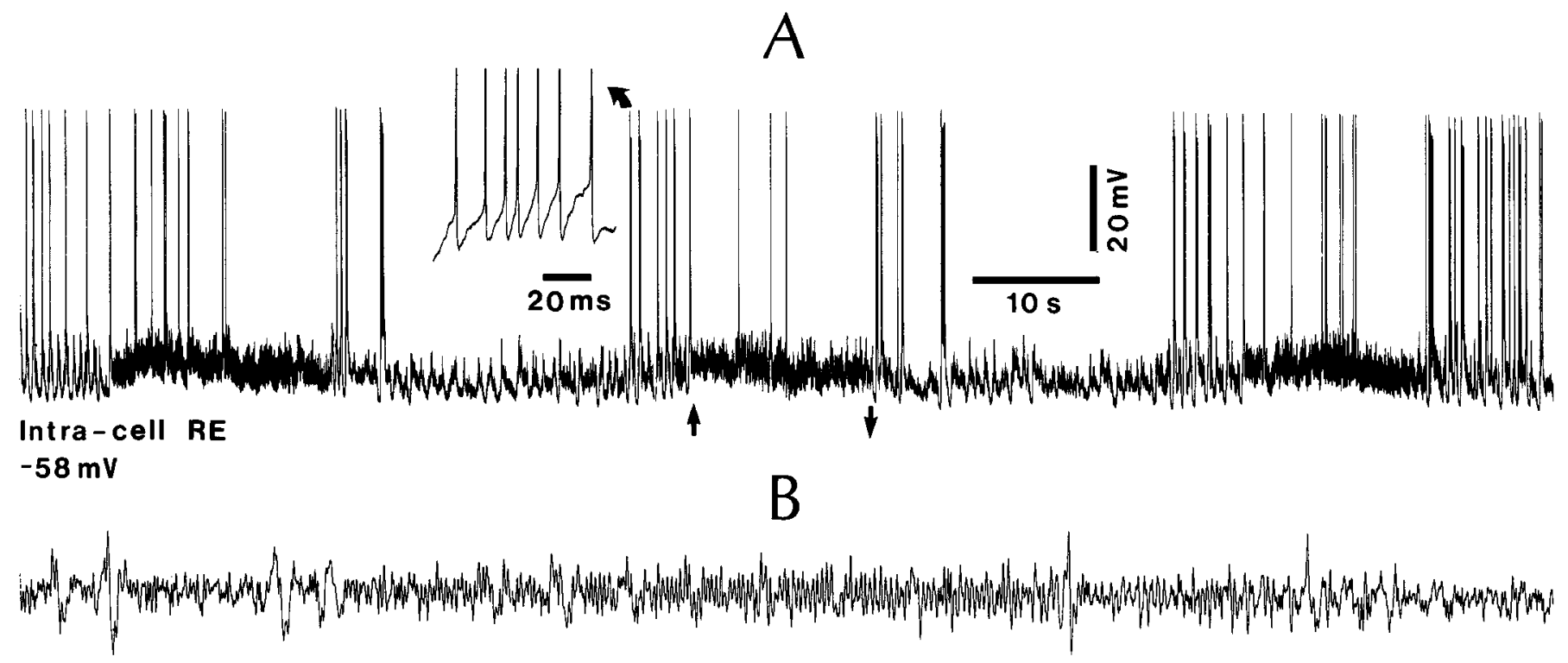

EEG-area 4

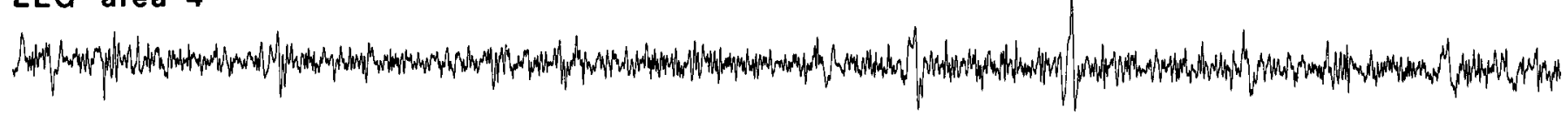

EEG-area 5
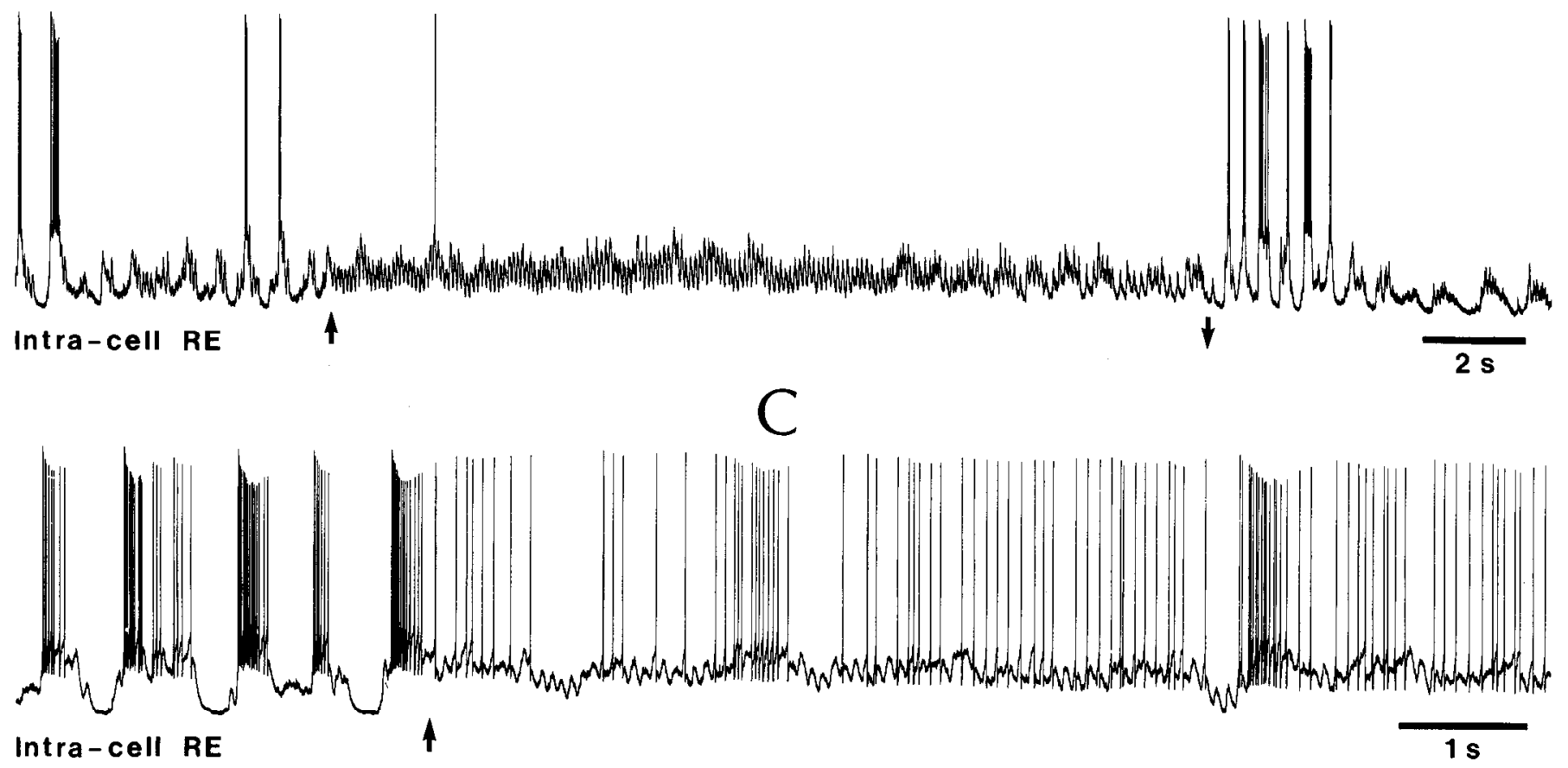

Figure 2. Cyclic episodes at $\approx 10 \mathrm{~Hz}$ in RE thalamic neuron. Intracellular recording in the rostrolateral part of RE nucleus. $A$, Three such episodes (the middle one marked between arrows), each lasting for $\approx 15 \mathrm{sec}$, recurring periodically every $\approx 40-45$ sec. One spike burst is expanded (oblique arrow) to display the typical acceleration-deceleration feature of RE cell bursts. $B$, One episode is expanded together with EEG activity from cortical areas 4 and 5 . The duration of this event (between arrows) was $\approx 17 \mathrm{sec}$. RE cell activity consisted of regular waves at $\approx 10 \mathrm{~Hz}$ associated with slight depolarization. Their frequency closely corresponded to that of EEG waves from area 4, grouped within a similar rhythmic event. $C$, Another episode (starting at arrow) during which most wavelets $(\approx 10 \mathrm{~Hz})$ of RE cell gave rise to action potentials.

those negative potentials and the sudden change in frequency marked a sharp contrast with the background activity. The episode eventually led to complexes of depth-negative spiky deflections interrupted by depth-positive slow waves recurring at a frequency of $2.5-4 \mathrm{~Hz}$ (Fig. $1 B$, d.c. trace from arca 5). In those instances in which the spiky negative potentials at 10-15
$\mathrm{Hz}$ were not interrupted by slow positive waves (see first episode in Fig. $1 C$ ), stimulation of appropriate thalamic nuclei succeeded in inducing slow $(\approx 0.3 \mathrm{sec})$ positive waves during which the negative components were suppressed (second episode in Fig. $1 C$ and inset).

(2) Cortical neurons discharged in close time relation with the 

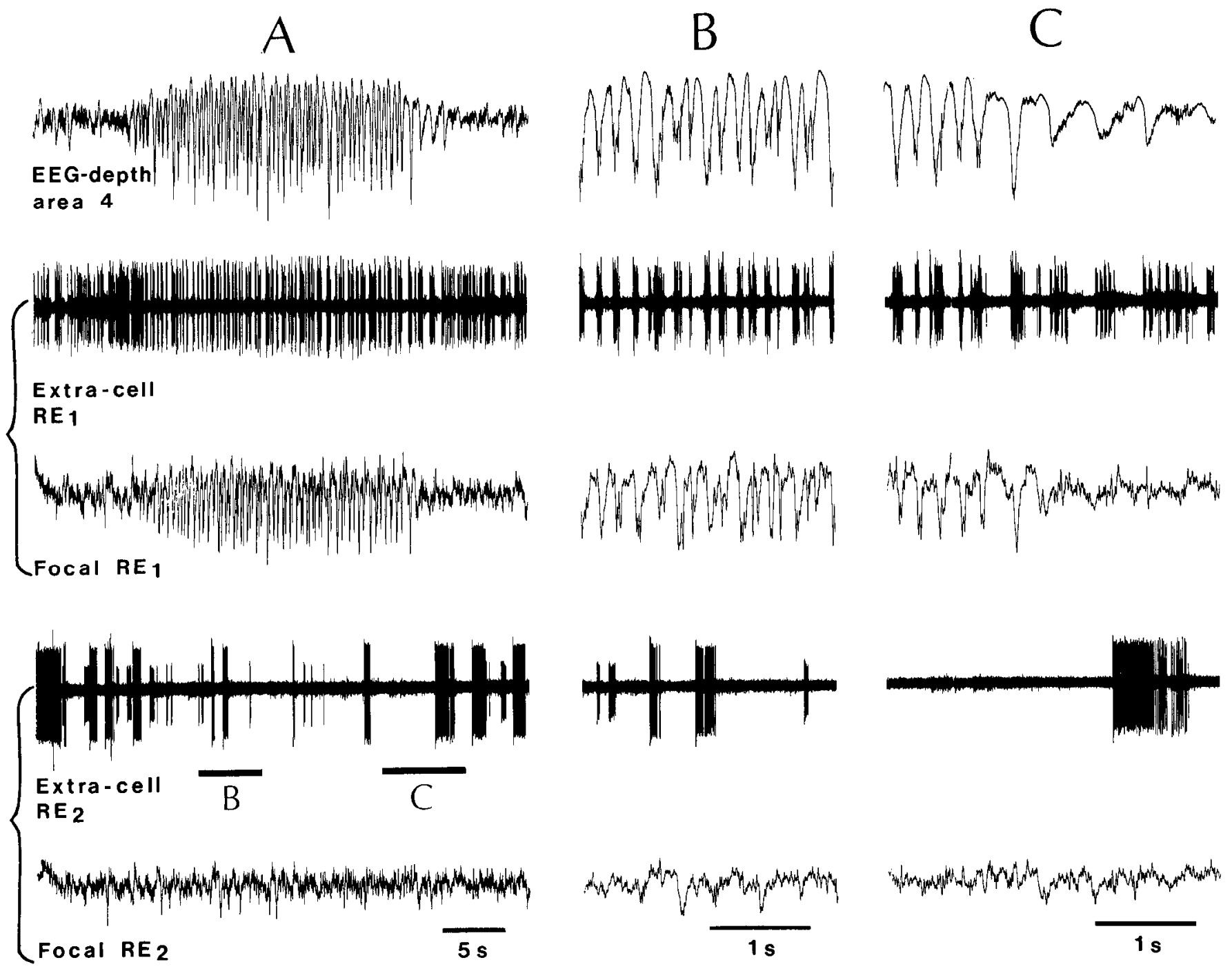

Figure 3. Relations between cortical synchronization episode and activities of RE thalamic cells. $A$, Simultaneous recording of depth-EEG activity in lateral precruciate motor cortex and unit discharges combined with focal waves in two foci $\left(R E_{1}, R E_{2}\right), 1.2 \mathrm{~mm}$ apart, within the rostral RE thalamic pole. $B$ and $C^{\prime}$ (marked on $R E_{2}$ trace) are expanded at right.

surface EEG and the field potentials recorded through the same microelectrode (Fig. 1B). Their short spike trains, recurring rhythmically at $10-15 \mathrm{~Hz}$, were eventually interrupted by periods of silenced firing, corresponding to the slow positive waves observed in the d.c. recording. Toward the end of the paroxysmal episode, the neurons discharged at $2.5-4 \mathrm{~Hz}$, in close time relation to EEG and local field potentials (Fig. $1 B$ ).

(3) A subsample of thalamic cells $(n=58)$ were entrained in the paroxysmal episodes. The intracellularly recorded rostral RE neuron illustrated in Figure 2 displayed cyclic episodes consisting of depolarizing wavelets at $\approx 10 \mathrm{~Hz}$, recurring every $\approx 40$ $45 \mathrm{sec}$, related to episodes of similar frequencies in the cortical EEG recorded from area 4. However, other thalamic neurons did not show alterations in discharge patterns and frequencies during the cortical paroxysms. Thus, some RE and dorsal thalamic neurons continued to discharge without reflecting the ongoing paroxysm in related cortical areas (see RE cell in Fig. 1C). Recordings from different foci in the rostrolateral sector of the RE nucleus also revealed that one neuron and the simultaneously recorded field potentials were entrained at the frequency of cortical paroxysm, whereas other RE neurons did not change their activities and the focal waves were similarly not affected (Fig. 3, compare $\mathrm{RE}_{1}$ to $\mathrm{RE}_{2}$ ). Although the discharge patterns of some thalamic single neurons did not change during the cortical paroxysmal synchronizations, the amplitudes of field potentials recorded through the same microelectrodes could increase and became spiky during those episodes (see RE and CL focal waves in Fig. $1 B$ ). In the latter cases, the thalamic activity lagged the onset of the cortical episode and outlasted its end by $2-5 \mathrm{sec}$.

(4) RE neurons discharge relatively long spike bursts ( $>40$ $50 \mathrm{msec}$ ) during sleep-like EEG patterns, as compared to those of thalamocortical neurons $(5-20 \mathrm{msec})$ during the same behavioral state (Domich et al., 1986; Steriade et al., 1986), due to a special type of low-threshold $\mathrm{Ca}^{2+}$ current, T-current (Huguenard and Prince, 1992). When the paroxysmal episodes started, the RE cell spike bursts further increased their duration to $200 \mathrm{msec}$ and were temporally related to the spiky negative field potentials recorded from the depth of the cerebral cortex, while the preburst period of RE cell silenced firing corresponded to 


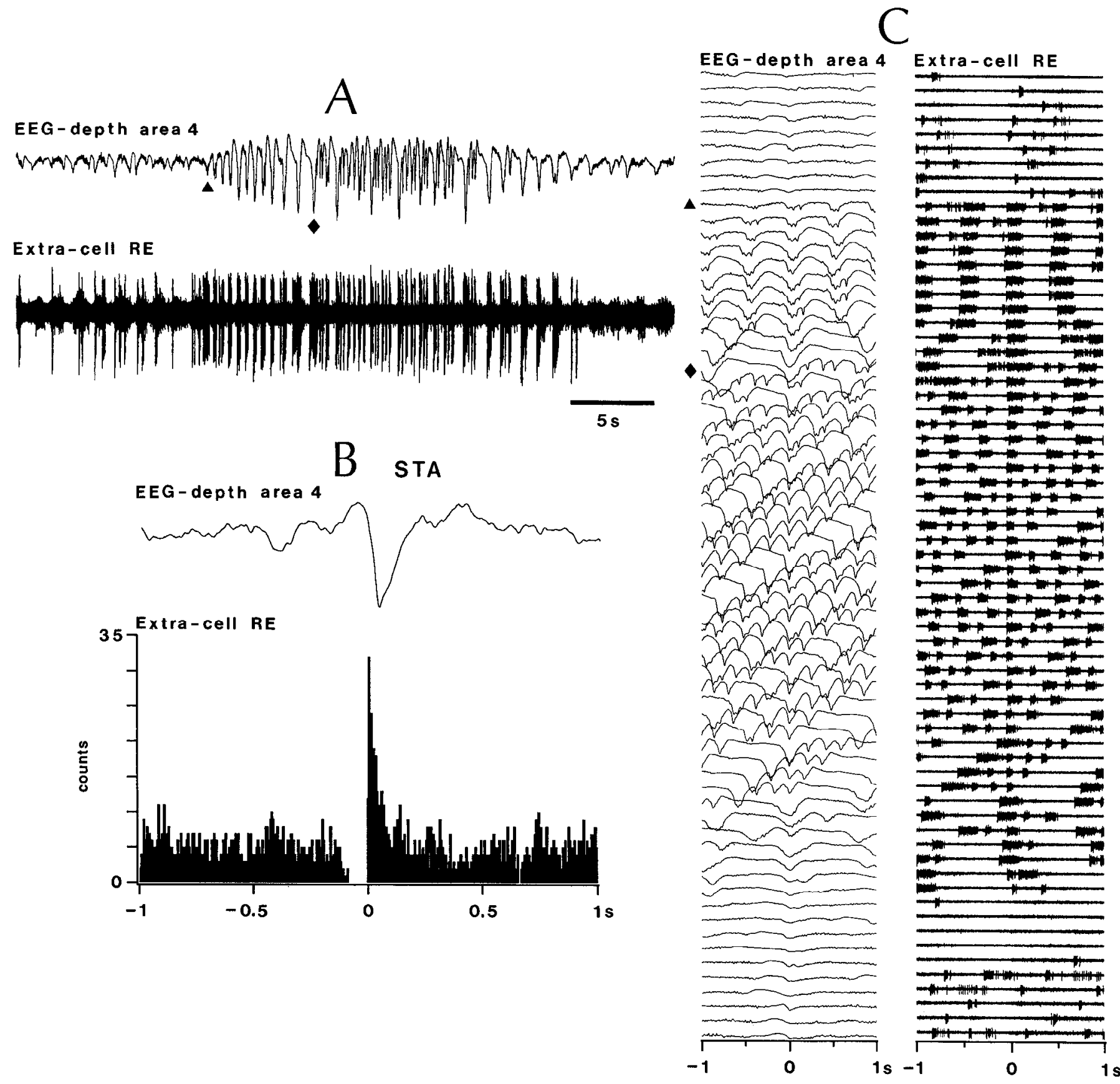

Figure 4. Resonant activities in cerebral cortex and RE thalamic nucleus. $A$, Paroxysmal episode recorded from depth of area 4 and RE cell, initiated at $\approx 1.5 \mathrm{~Hz}$ and reaching $\approx 4 \mathrm{~Hz}$ within the middle of the episode. $B$, Spike-triggered average (STA). RE cell spike bursts aligned at time zero and used to trigger depth-EEG waves. Note correspondence between preburst silenced firing and depth-positive EEG wave, and between RE cell excitation and depth-negative spiky EEG deflection. $C$, Sequential analysis of cortical EEG activity and related discharges of RE cell, triggered by the peak negativity of field potentials in the depth of area 4 (time zero) over a window of $1 \mathrm{sec}$ (to be read from top to bottom). Note usual spike bursts $(\approx 40 \mathrm{msec})$ of RE cell during sleep-like patterns preceding the paroxysmal episode (first nine traces), developing into longer-lasting spike bursts $(\approx 200 \mathrm{msec}$ ) during the initial part of the episode at $\approx 1.5 \mathrm{~Hz}$ (next 11 traces), and reduced duration of RE cell spike bursts (40-100 msec) during the cortical EEG complexes at $\approx 4 \mathrm{~Hz}$ (next 30 traces). $\triangle$ and in $C$ correspond to the same symbols in $A$.

the depth-positive cortical EEG wave (Fig. 4A,B). The sequential analysis in Figure $4 C$, in which both cortical EEG waves and RE cell discharges were aligned at time zero by the spiky depth-negative cortical potential, shows the development from sleep patterns (top nine traces) to the paroxysmal episode initiated at $\approx 1.5 \mathrm{~Hz}$ (next 11 traces, starting at the triangle), finally reaching a pattern of SW seizure at a frequency of $\approx 4 \mathrm{~Hz}$ (next
30 traces, starting at the diamond-shaped symbol). During this latter part of the episode, at $\approx 4 \mathrm{~Hz}, \mathrm{RE}$ cell seizure-like discharges were centered around the time zero, corresponding to the peak negativity of cortical waves which reflects excitation of area 4 cells.

(5) Simultaneous recordings of RE cells and neurons in related dorsal thalamic territories during the cortical paroxysmal epi- 


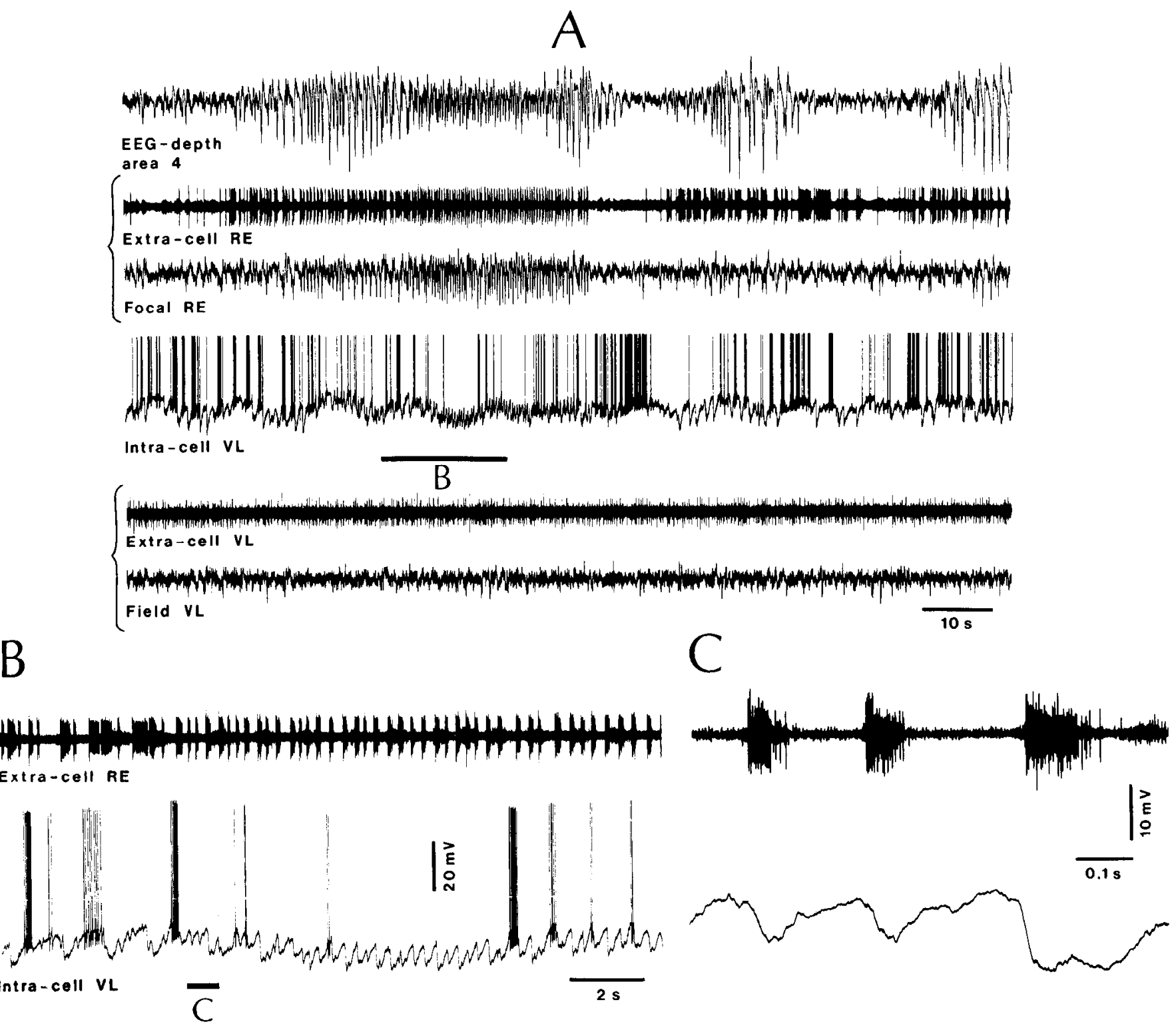
Intra-cell VL

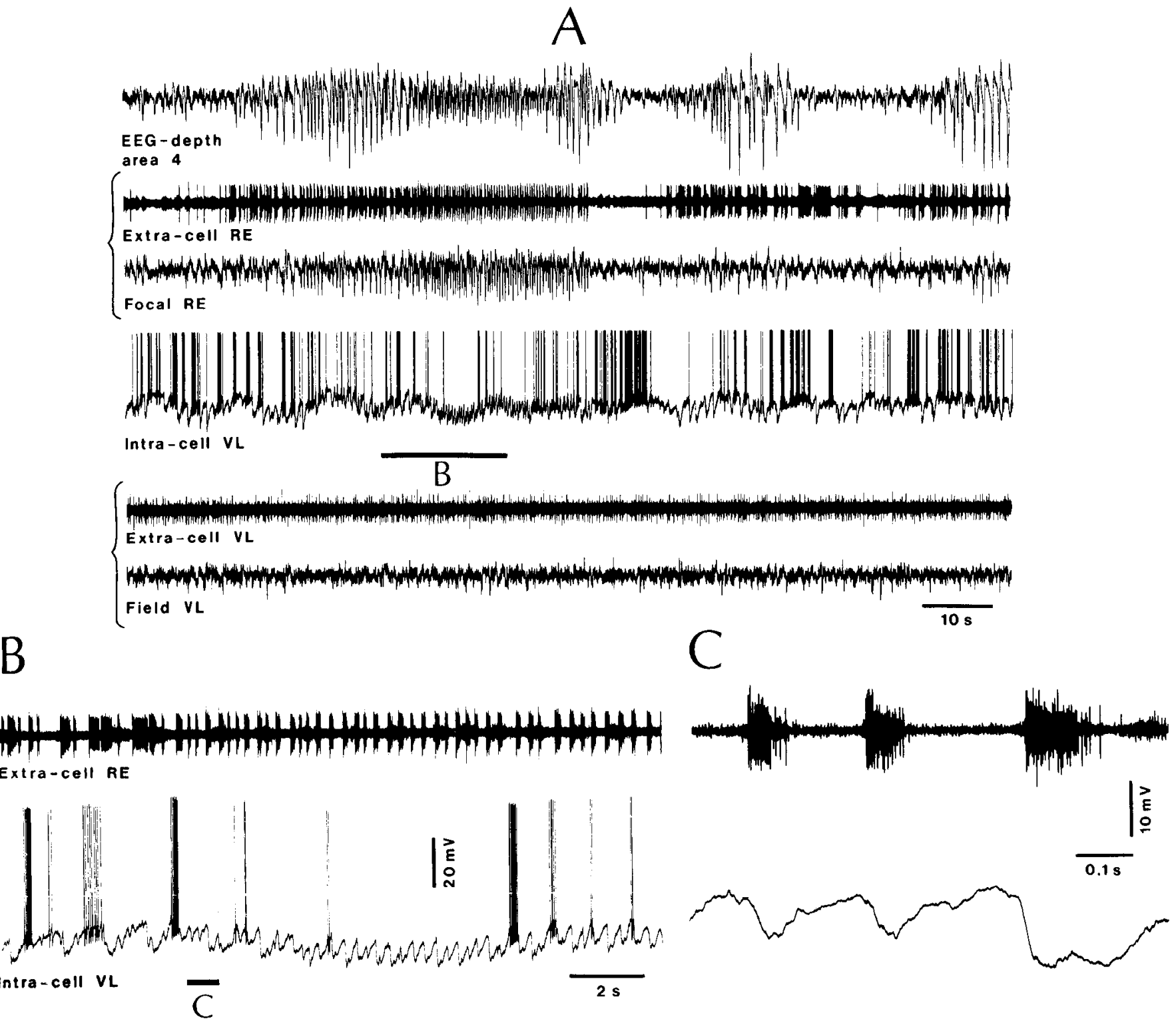

Figure 5. Synchronization episode with $\approx 3 \mathrm{~Hz}$ activity in neocortex and RE thalamic nucleus, and the reflection of RE cell bursts in TC neuron. $A$, The six simultaneously recorded traces represent EEG activity in the depth of lateral precruciate cortex, unit discharges and focal waves through the same microelectrode in the rostrolateral sector of the RE thalamic nucleus, and intracellularly recorded TC neuron in VL nucleus (spikes truncatcd). Part marked by $B$ is expanded below to show the close relation between spiky negative deflections of area 4 EEG complexes at $\approx 3 \mathrm{~Hz}$ and spike bursts of RE neuron, as well as between the latter and the time-locked hyperpolarizations in VL cell (see especially the transition from $<1 \mathrm{~Hz}$ to $3-4 \mathrm{~Hz}$ activity when VL cell undergoes tonic hyperpolarization). $C$, Durations and amplitudes of VL cell IPSPs are related to durations of RE cell spike bursts.

sodes reaching a frequency of $2-4 \mathrm{~Hz}$ consistently revealed a reciprocal (inverse) activity pattern in $\mathrm{RE}$ and $\mathrm{TC}$ neurons ( $n$ $=11$ ). Whereas RE cells exhibited spike bursts within the frequency of cortical paroxysms, TC neurons concomitantly displayed IPSPs at the same frequencies (Fig. 5A,B). In some instances, we could demonstrate a close relation between the duration of the extracellularly recorded spike bursts in RE cells and the duration of the IPSP in related TC neurons (Fig. 5C).

The analysis of the temporal sequence of events in simultaneously recorded activities from cortical EEG, and RE and TC neurons during a paroxysm at $\approx 3 \mathrm{~Hz}$ (Fig. 6) shows (1) the correspondence between the depth negativity in cortical EEG and the spike bursts of RE cells, on one hand, and the IPSPs associated with interruption of discharges in VL cell, on the other (Fig. 6A, activities aligned at time zero by RE cell spike bursts); and (2) the RE cell spike bursts and VL cell IPSPs being preceded $(\approx 10 \mathrm{msec})$ by a first negativity in the depth-cortical EEG (see second trace, first derivative, in Fig. $6 B$ ). The Lissajous figure in Figure $6 C$, depicting the evolution of $\mathrm{VL}$ intracellular activity against the positive-negative potentials of EEG during the cortical paroxysm, indicates that (1) at a time when the depth EEG began its excursion toward the peak negativity (triangle corresponding to the same symbol in Fig. 6A), the VL cell did not yet initiate the IPSP; (2) afterward, the VL cell hyper- 


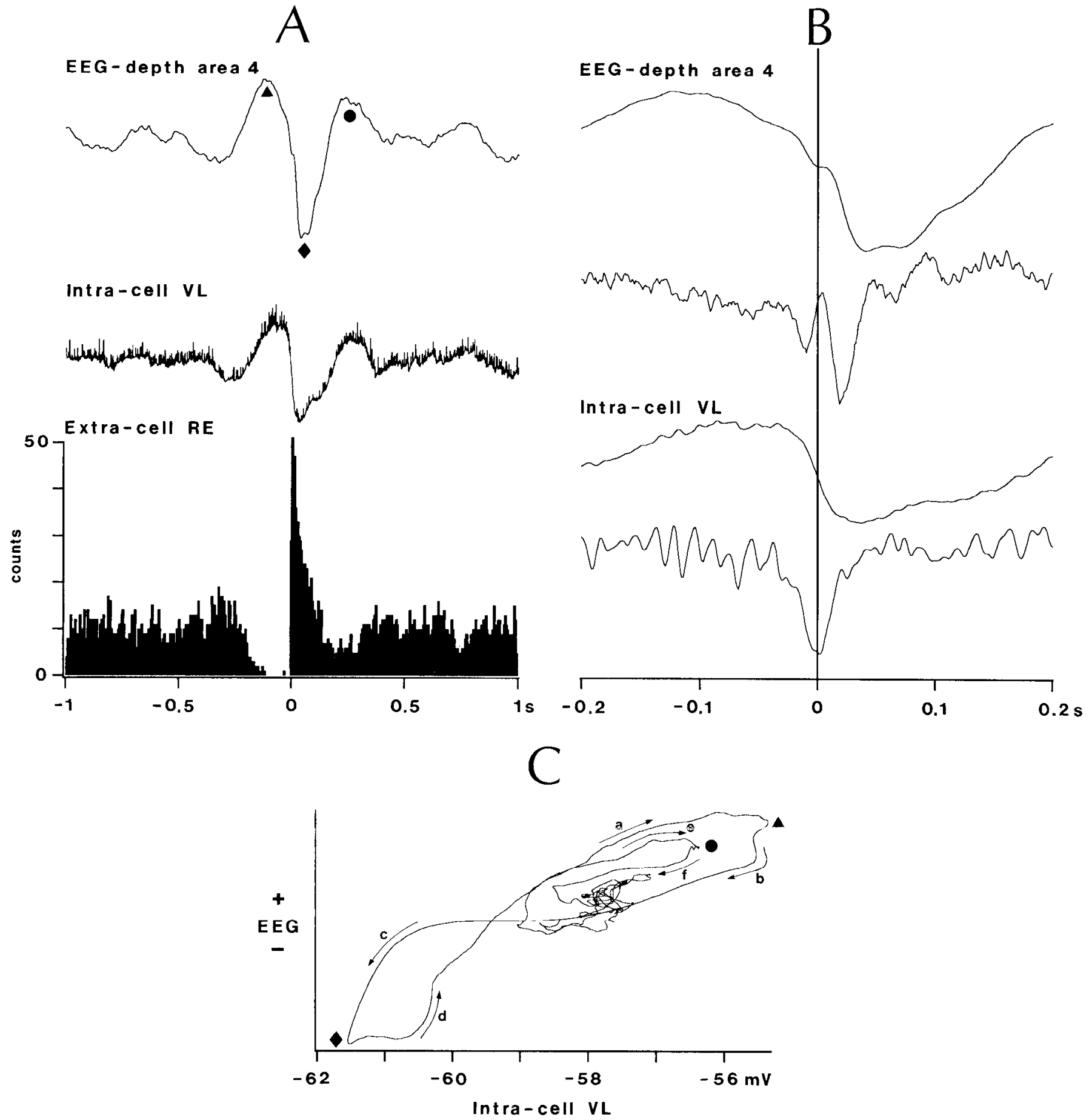

Figure 6. Temporal sequence of events in motor cortical EEG as well as rostrolateral RE and VL cells during a paroxysm at $\approx 3 \mathrm{~Hz}$. $A$, Spiketriggered averages (RE cell spike bursts at time 0 ) of depth EEG in area 4 and intracellularly recorded VL activity. Symbols on EEG trace correspond to those in C. B, Rclation betwcen the pcak of IPSP in VL cell (time zero) and EEG events. In both EEG and VL activities, bottom trace is first derivative. $C$, Lissajous figure illustrating the evolution of VL intracellular activity (abscissa) against the positivity and negativity of cortical EEG (ordinate). The trace should be followed along the arrows from $a$ to $f$. $\Delta$,

polarized by $\approx 5 \mathrm{mV}$, while the slope of EEG negativity no longer changed. These changes illustrate that activity changes in the motor cortex precede those in VL, leading to IPSPs in TC cells presumably mediated by activation of RE cells (see also Figs. $5,6 A$ ). Both the EEG and VL cell activity returned to control values (center cloud in Fig. $6 C$ ).
Entrainment and synchronization of thalamocortical neurons in $S W$ paroxysms at $2-4 \mathrm{~Hz}$

Out of 43 recorded dorsal thalamic neurons, $18(\approx 40 \%)$ discharged spike bursts in good time relation with SW seizures at $2-4 \mathrm{~Hz}$ in related cortical areas. 
A1

(n)
EEG-surf. a rea 4

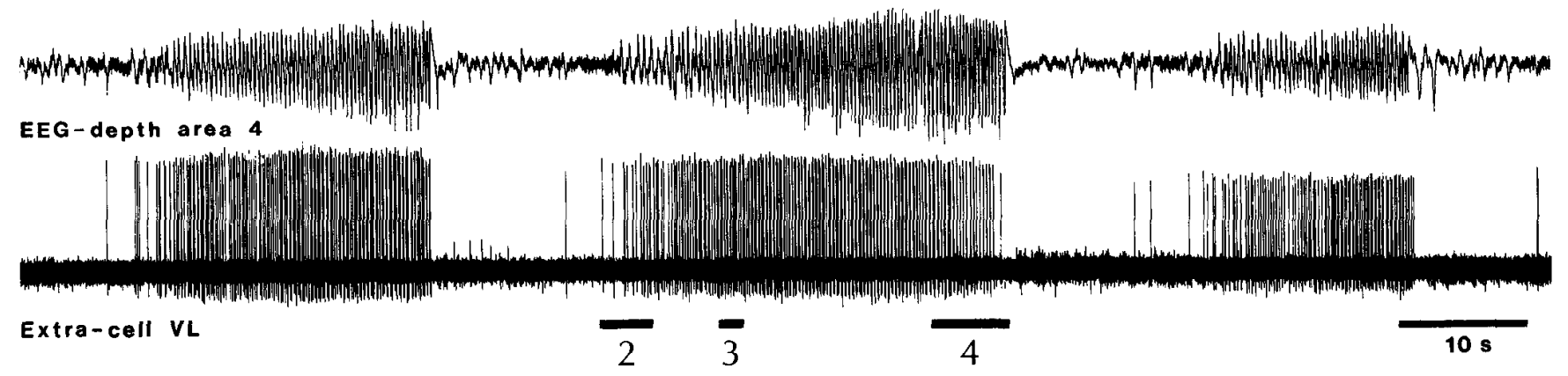

2

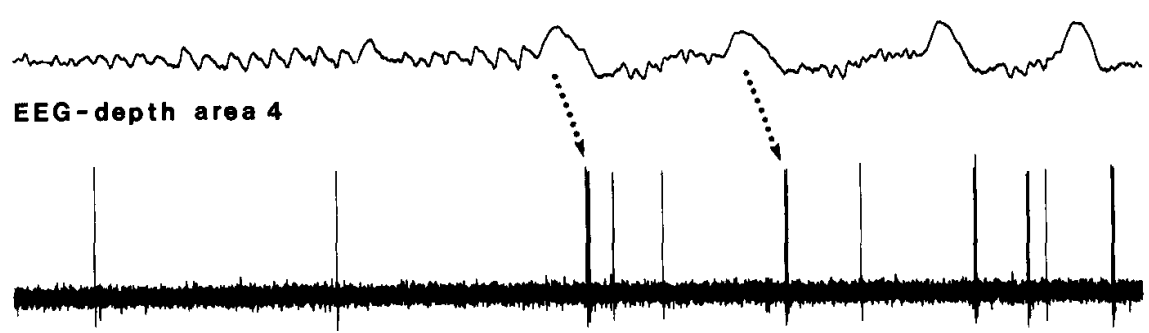

3

Extra-cell VL

4
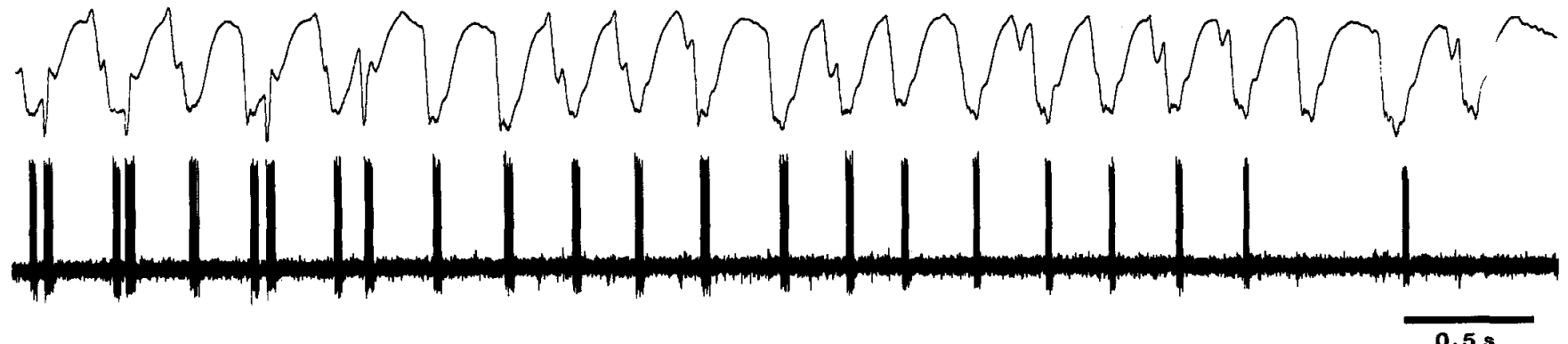

B1

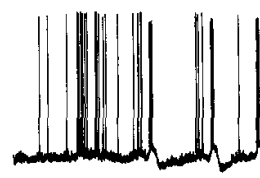

Intra-cell VL

$-56 \mathrm{mV}$

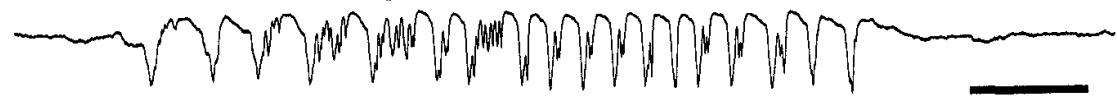

EThG

$2 \mathrm{~s}$
2
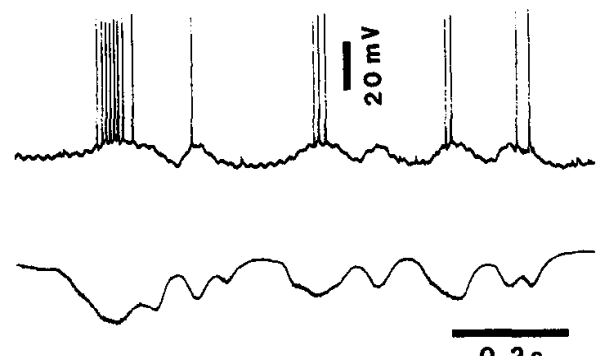

Figure 7. Cyclic paroxysmal synchronization episodes in corticothalamic networks leading to SW discharges at 3-4 Hz. Al, The three simultaneously recorded traces show surface and depth EEG from precruciate area 4, and extracellularly recorded VL TC neuron. Three paroxysmal episodes separated by $\approx 40-45 \mathrm{sec}$. Parts marked by $A 2-A 4$ in the middle episode are expanded below. Dotted lines and arrows in $A 2$ tentatively indicate the sequence of depth-positive cortical waves followed by spike bursts in VL cell that initiate the paroxysm. $B$, Intracellular recording of a rostral $\mathrm{VL}$ cell showing SW activity at $\approx 2 \mathrm{~Hz}$, related to mass discharges recorded from a macroelectrode inserted more posteriorly in the VL nucleus. Part marked by $B 2$ is expanded at right to show the close relation between depolarizations and field negativities. 

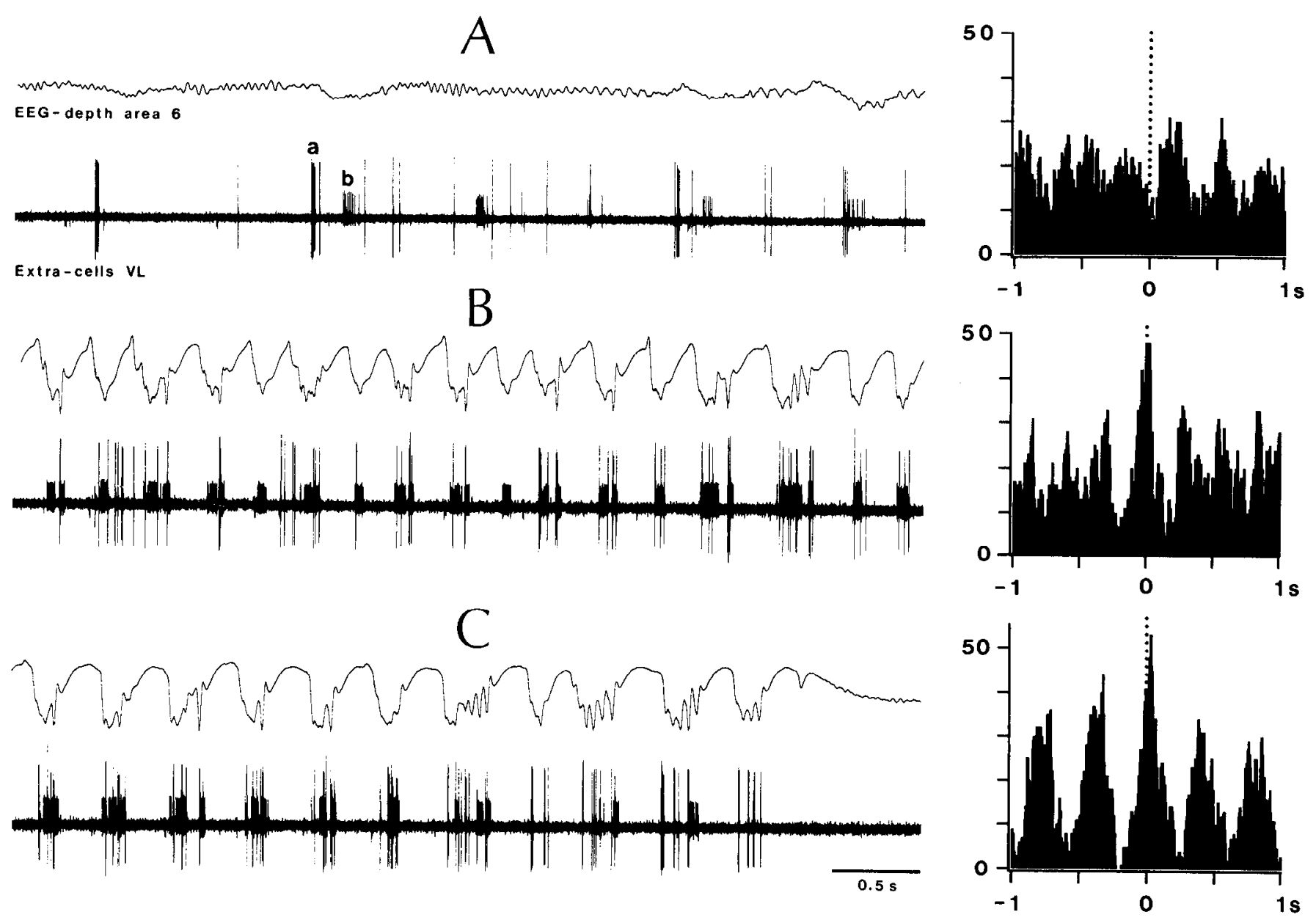

Figure 8. Synchronization of thalamic neurons during SW seizure. Extracellular recording of 2 VL thalamic cells through the same microelectrode. $A$, Asynchronous discharges prior to SW seizure. $B$ annd $C$, SW seizure at $\approx 2.5-3 \mathrm{~Hz}$. The two cells displayed slight signs of synchronization during the early phase $(B)$ and were fully synchronized toward the end of the seizure $(C)$. At right, cross-correlograms between cells $a$ and $b(a$ at time zero) during each of these three epochs. Note close relation between spike trains of both VL cells and the "spike" EEG component, as well as between their silenced firing and the "wave" depth-positive component of SW complexes from the precruciate cortical area 6.

Figure 7 shows that prolonged $(\approx 25-30 \mathrm{sec})$ paroxysmal episodes, recurring every $\approx 40-45 \sec$ (Fig. $7 A 1$ ), started with depthpositive cortical waves in motor cortical area 4 , reliably followed by spike bursts in a TC VL cell (Fig. 7A2). This pattern developed into SW activity at $\approx 3-4 \mathrm{~Hz}$, with spike bursts of the VL neuron related to the spiky component of cortical EEG complexes and with silenced firing corresponding to the depth-positive cortical waves (Fig. $7 A 3, A 4$ ).

That at least some pools of dorsal thalamic neurons discharged synchronously during SW cortical seizures at $2-4 \mathrm{~Hz}$ was indicated by simultaneous recordings within different foci in dorsal thalamic nuclei $(n=9)$. The intracellularly recorded VL neuron in Figure $7 B$ displayed spike bursts at $\approx 2.5-3 \mathrm{~Hz}$, separated by hyperpolarizations, simultaneously with a similar type of field activity recorded within the same nucleus, $\approx 1.5$ $\mathrm{mm}$ more posteriorly. The cellular depolarizations were time related to the field negativities, whereas the hyperpolarizations corresponded to field positivities (Fig. 7B2). We also obtained evidence that the synchronization process was progressively reached during the SW seizure. Indeed, the two VL neurons recorded through the same extracellular microelectrode (Fig. 8) discharged randomly before the SW episode (Fig. $8 A$ ), were partially coupled during the early part of the SW seizure (Fig. $8 B$ ), and became fully synchronized towards the end of the seizure (Fig. 8C). The cross-correlograms taken from these different epochs document the progressive evolution from sleep to SW activities.

The idea that cortical inhibition primes paroxysmal episodes, as suggested in Figure 7A2, is supported by the simultaneous intracellular recording of an S1 cortical cell and extracellular recordings of neurons from two foci of the VP thalamic complex (Fig. 9). The seizure, which eventually reached an SW pattern,

Figure 9. Inhibition leads to paroxysmal synchronization in corticothalamic activities. $A$, Five simultaneously recorded traces showing surface and depth EEG from S1 cortex, intracellular recording of S1 cell $(0.6 \mathrm{~mm})$, and two extracellularly recorded VP thalamic neurons. The paroxysmal activity was initiated by hyperpolarization of the $\mathrm{S} 1$ cell, related to depth-positive EEG waves (arrowhead). $B$, Same neurons as in $A$. VP stimuli (arrowheads) elicited hyperpolarizations in S1 cell and depth-positive EEG waves as well as periods of silent firing followed by rebound spike bursts in the two VP neurons, eventually leading to a similar self-sustained paroxysm as in $A$. 


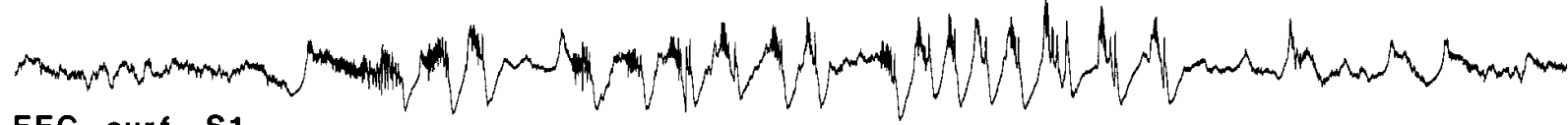
EEG-surf. S1

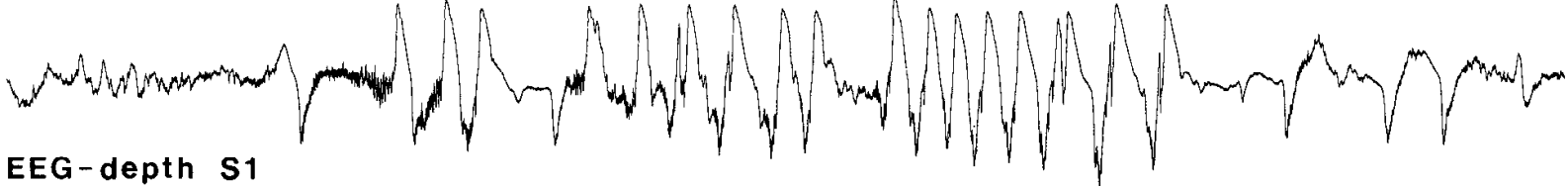
Intra-cell S1

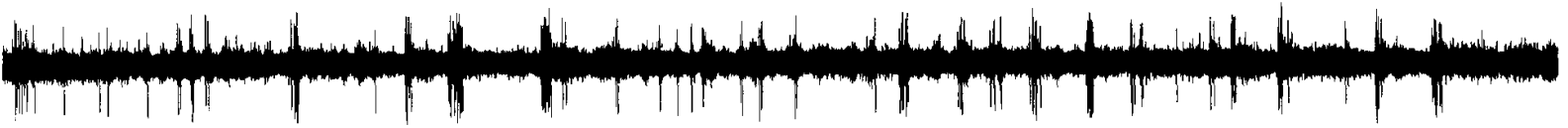
Extra-cell VP1

Extra-cell VP2
Es

B

EEG-surf. S1 EEG-depth. S1 $\underset{\substack{\text { Intra-cell } s 1 \\-65 \mathrm{mV}}}{\operatorname{man}}$

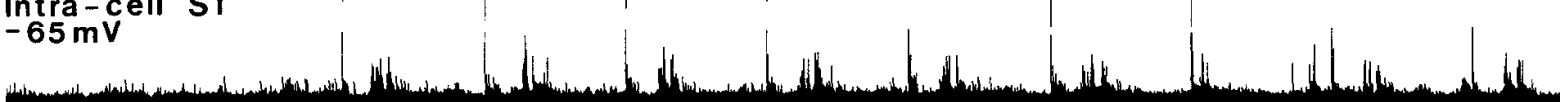
$\underset{\text { Extra-cell VP1 }}{\text { Extra-cell VP2 }}$ 


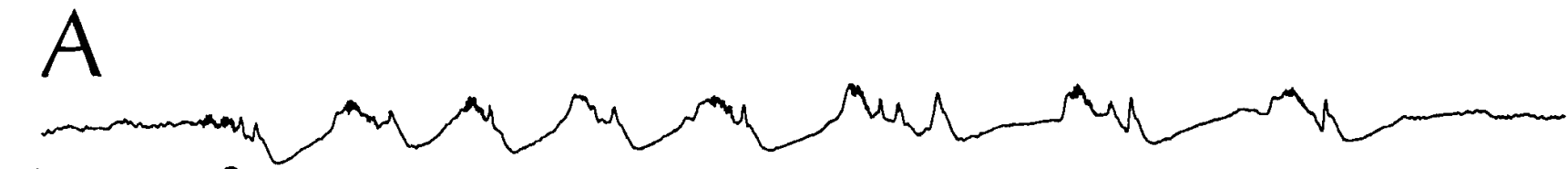

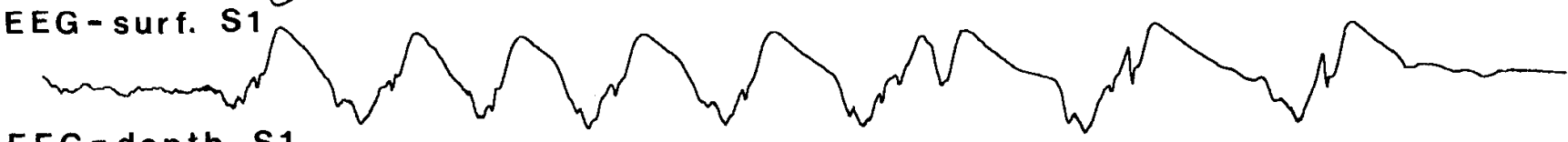

EEG-depth $\mathbf{S 1}$
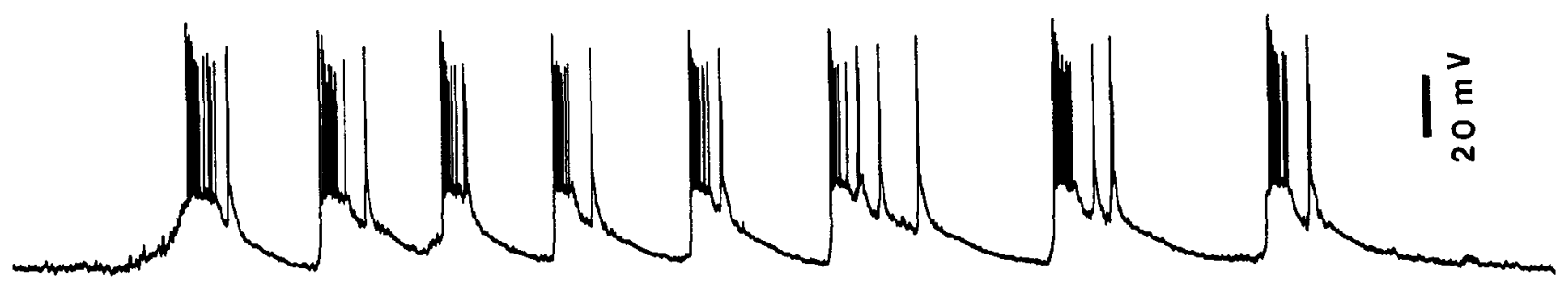

Intra-cell $\$ 1$

$-65 \mathrm{mV}$
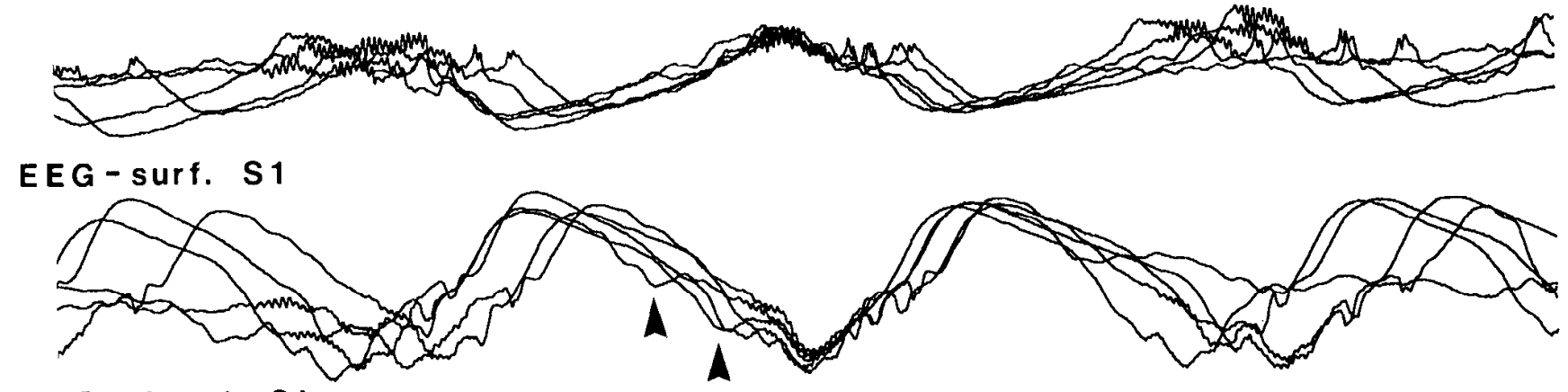

\section{EEG - depth $\mathrm{S1}$}

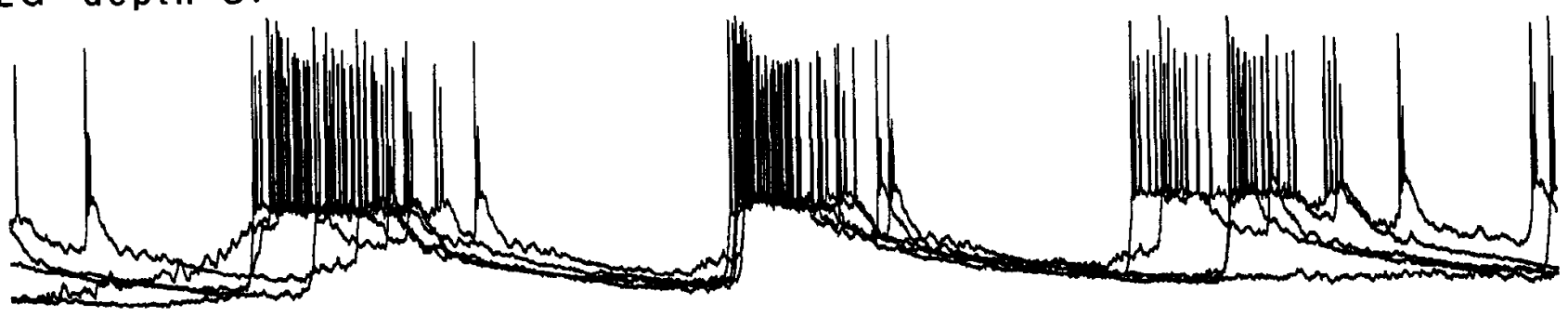

Intra-cell $\mathbf{S 1}$

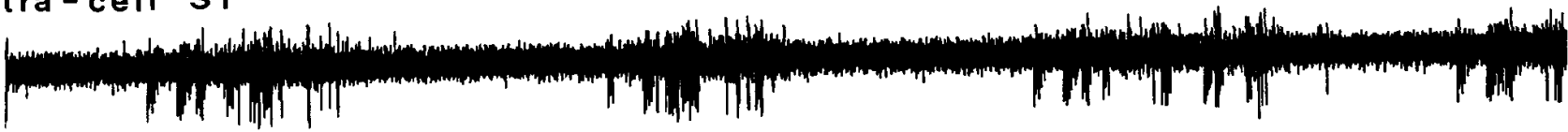

\section{Extra-cell VPI}

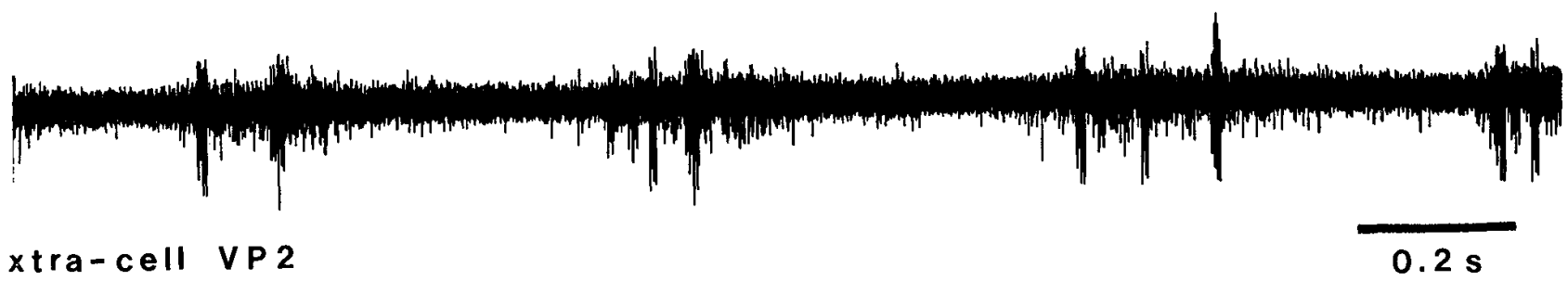

Figure 10. Relations between SW seizure in cortical S1 area and VP thalamic nucleus. $A, \mathrm{SW}$ complexes, $\approx 2 \mathrm{~Hz}$, in the surface and depth EEG in $\mathrm{S} 1$ cortex, related to paroxysmal depolarizations of intracellularly recorded $\mathrm{S} 1$ neuron. $B$, Same EEG and $\mathrm{S} 1$ cell activities as in $A$, recorded simultaneously with two multiunit VP thalamic activities, $\approx 1.5 \mathrm{~mm}$ apart. EEG waves from the cortical surface and depth, and intracellular cortical 
started with a hyperpolarization of S1 neurons, associated with a depth-positive EEG wave (arrowhead in Fig. 9A). Thereafter, the rhythmic spike bursts followed by afterhyperpolarizations in the cortical neuron (and associated with high-amplitude spiky negative and slow positive field EEG potentials from the depth of S1) occurred during a pronounced depolarization of S1 cells and were time related to spike bursts of both VP neurons occurring at the same frequency $(\approx 2 \mathrm{~Hz}$ ). Figure $9 B$, depicting the same cell group, shows that thalamic stimuli, delivered through an electrode inserted into the VP complex, elicited large hyperpolarizations in the $\mathrm{S} 1$ neuron (associated with depth-positive field potentials) as well as postinhibitory rebound spike bursts in both VP cells. The VP-evoked cortical hyperpolarizations grew in size and finally gave rise to a paroxysmal discharge resembling the spontaneously occurring seizure depicted in Figure $9 A$.

Whereas the majority of simultaneous cortical and thalamic intracellular, unit extracellular, and/or field potential recordings showed that thalamic inhibitory-rebound sequences clearly followed cortical events (see Figs. $7 A 2,14$ ), in some cases the spike bursts of TC cells jittered around the time zero of the corticofugal excitatory event. The simultaneously recorded activities in Figure $10 B$ depict five superimpositions triggered by the peak negativity recorded from the depth of $\mathrm{S} 1$ cortex during the episode illustrated in Figure $10 \mathrm{~A}$. The spike bursts of both extracellularly recorded VP neurons occurred around the onset of paroxysmal depolarizations in the $\mathrm{S} 1$ neuron, but sometimes they preceded the peaked cortical excitatory activity by intervals as long as $0.1 \mathrm{sec}$, in association with isolated depth-ncgative EEG wavelets in the cortex (arrowheads).

\section{Hyperpolarizations of thalamocortical neurons during cortical SW seizures}

Twenty-five out of 43 dorsal thalamic neurons $(\approx 60 \%)$ were tonically as well as phasically hyperpolarized during the cortical SW seizure. This result was first suggested by silent firing of extracellularly recorded TC neurons throughout the cortical paroxysms $(n=14)$ and was finally demonstrated by intracellular recordings of TC cells $(n=8)$, sometimes in conjunction with simultaneous intracellular recordings from cortical neurons ( $n$ =3).

We found a good relation between the duration and/or amplitude of SW seizures in field and intracellular cortical recordings, on one hand, and the extent of hyperpolarization in TC ncurons, on the other. Embryonic hyperpolarizations of thalamic neurons could well have remained undetected if the focal cortical EEG were not simultaneously recorded. This is shown in Figure $11 \mathrm{~A}$, illustrating a quite short $(\approx 2 \mathrm{sec})$ episode of cortical SW complexes at $\approx 2.5 \mathrm{~Hz}$ in area 4 , accompanied by a barely visible hyperpolarization in a VL TC cell. Subsequently, progressively longer cortical SW seizures were faithfully accompanied by VL hyperpolarizations with durations which were identical to those of cortical SW seizures (Fig. 11B,C). The thalamic hyperpolarization started at the onset of the cortical $\mathrm{SW}$ seizure, was tonic, $\approx 15 \mathrm{mV}$, and phasic repetitive events at $\approx 5 \mathrm{~Hz}$ were superimposed upon it (see Fig. $11 \mathrm{C}$ ). The $V_{m}$ resumed immediately after the end of the cortical seizure.
Similar findings were observed with more developed cortical SW seizures. In those instances, we were able to detect the corticothalamic events associated with the initiation, development, and cessation of seizures. Thus, the sleep-like patterns were progressively transformed into higher-amplitude depthpositive (inhibitory) cortical waves from area 4 and, simultaneously, the $V_{m}$ of the VL TC neuron underwent a progressive hyperpolarization, up to $8 \mathrm{mV}$ more negative than the prior level (Fig. 12A,B). With further development of SW cortical complexes at $\approx 2.5-4 \mathrm{~Hz}$, the VL neuron remained hyperpolarized by $12-14 \mathrm{mV}$, while episodic higher-frequency $(10 \mathrm{~Hz})$ cortical waves were reflected as depolarizing events with the same frequency in the thalamic neuron (right side of Fig. 12C). Interestingly, the end of seizure and silenced activity in cerebral cortex was followed by depolarization and increased firing of the VL thalamic neuron (Fig. 12A). Occasional depth-negative deflections in the cortical field potential recording gave rise to short IPSPs in the VL cell (see right side of Fig. 12A). It should also be mentioned that the intracellular events in the ipsilateral thalamus more faithfully reflected the cortical seizure than the EEG recorded from the homotopic focus of the contralateral area 4, which was entrained only $10 \mathrm{sec}$ later.

Finally, dual intracellular recordings in the cortex and the appropriate thalamic nucleus demonstrated that the main events triggered in TC neurons by paroxysmal depolarizations of cortical cells were repetitive IPSPs, and that a tonic hyperpolarization of TC neurons was associated with the rhythmic discharges of cortical neurons throughout the SW episodes. The seizure illustrated in Figure $13 \mathrm{~A}$ was initiated by high-amplitude positive-negative EEG waves in the depth of area 4, associated with large hyperpolarizing-depolarizing envelopes in the area 4 cell as well as distinct hyperpolarizations in the VL cell; yet no visible corresponding signs were detected at that early time on the surface-cortical EEG or in the homotopic focus of the contralateral motor cortex. With further development of the cortical SW seizure, the VL thalamic cell became tonically hyperpolarized by $\approx 12 \mathrm{mV}$. Each paroxysmal depolarization in the cortical neurons, superimposed by repetitive spike bursts and afterhyperpolarizations at $\approx 10 \mathrm{~Hz}$, was accompanied by a sequence of thalamic events initiated by a small-amplitude EPSP, immediately cut off by rhythmic IPSPs at $10 \mathrm{~Hz}$ (see last intracellular trace in Fig. 13B).

These dynamic corticothalamic processes during the SW seizure are further depicted in Figure 14. The sequential analysis of depth-cortical EEG in area 4 (left column), intracellularly recorded area 4 cell (middle column), and intracellularly recorded VL thalamic cell (right column), all aligned at time zero representing the peak negativity of depth-cortical waves, shows that (1) before the paroxysm (first seven traces, from top to bottom) a sleep-like slow rhythm was present in the EEG and was associated with prolonged depolarizations and hyperpolarizations in the cortical ccll; (2) the initial part of the seizure (traces 8-20) consisted of SW cortical complexes at $2 \mathrm{~Hz}$ and corresponding hyperpolarizations in TC cell; (3) the seizure continued (traces $21-35)$ with rhythmic $(\approx 0.9 \mathrm{~Hz})$ paroxysmal depolarizations, including $\approx 10 \mathrm{~Hz}$ spike bursts in cortical cell, that were reflected in the VL neuron as rhythmic IPSPs at 10

and extracellular thalamic activities were triggered by the peak negative deflection of the "spike" EEG component at the cortical depth. Note correspondence between paroxysmal depolarizations of SI cell and "spike" component. The discharges of both VP cells occurred around the peak excitatory activity in S1 cortex, but in some instances preceded it by $\approx 0.1 \mathrm{sec}$, in association with depth-negative EEG wavelets (arrowheads). 
A

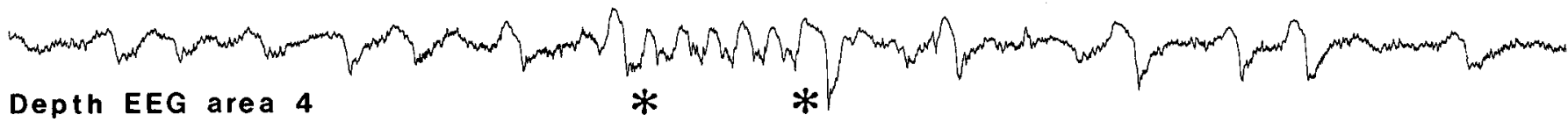

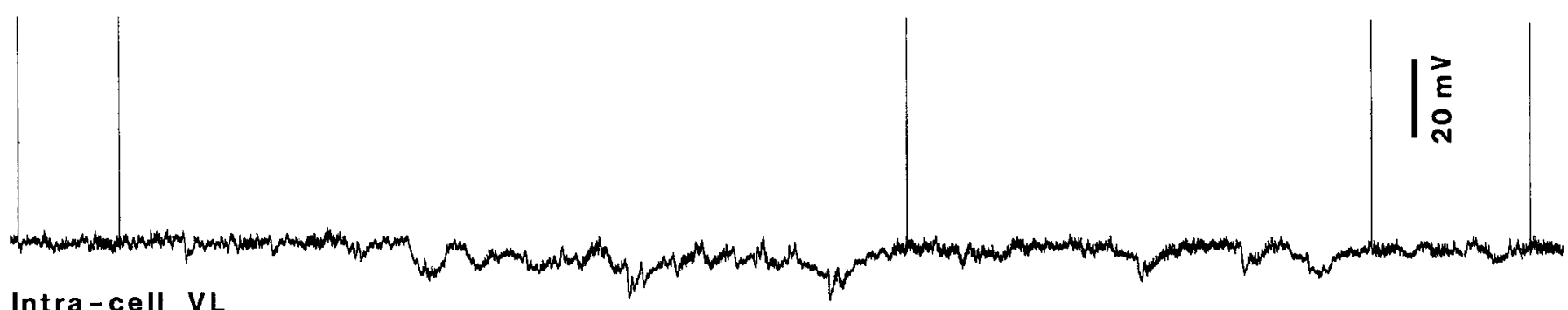

Intra-cell VL

$-58 \mathrm{mV}$

B

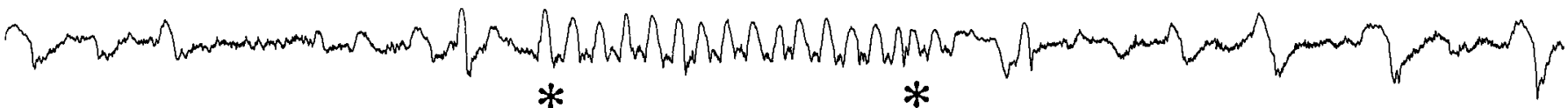

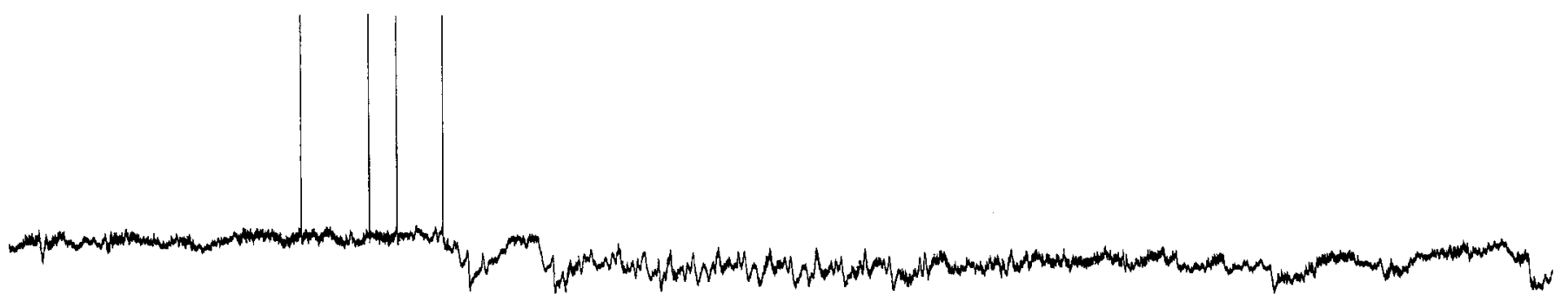

$C$

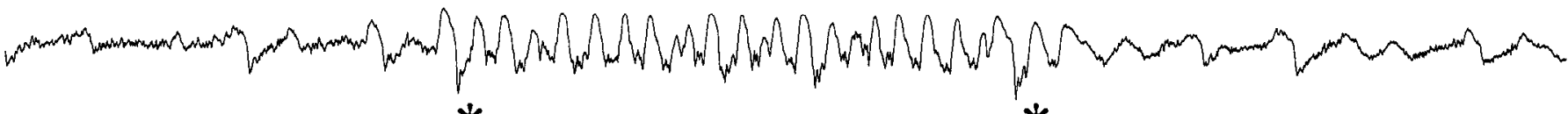
*

*

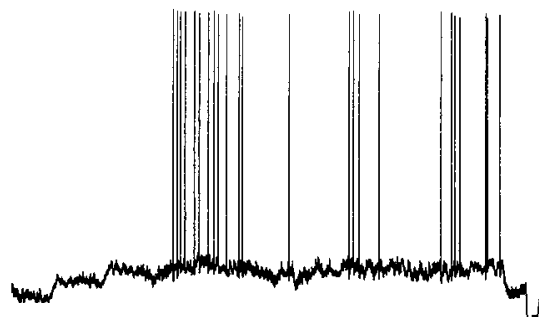

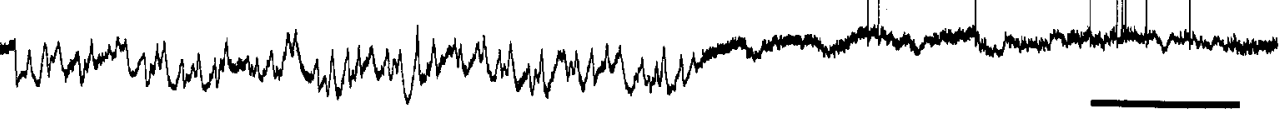

$2 \mathrm{~s}$

Figure 11. Hyperpolarization of thalamic cell during cortical SW seizures. EEG from the depth of cortical area 4 and intracellularly recorded VL TC neuron. Development from embryonic SW activity $(A$, between asterisks) to longer-lasting SW seizures at $\approx 2-2.5 \mathrm{~Hz}(B$ and $C$, between asterisks). 
A

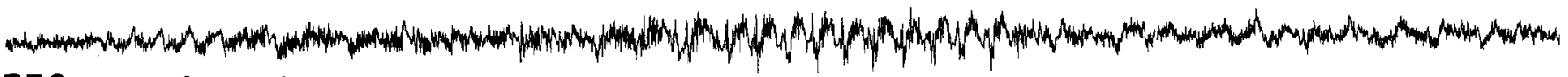
EEG area 4 - contra

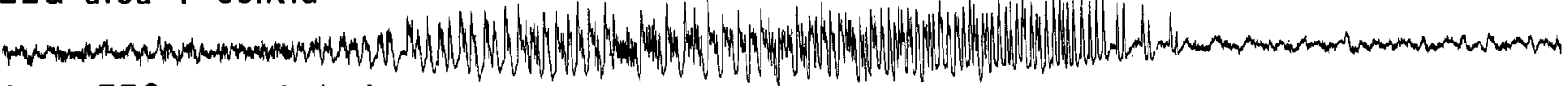
Surf. EEG area 4-ipsi

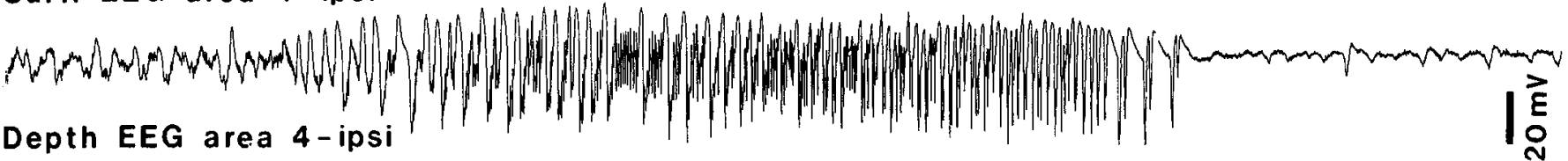

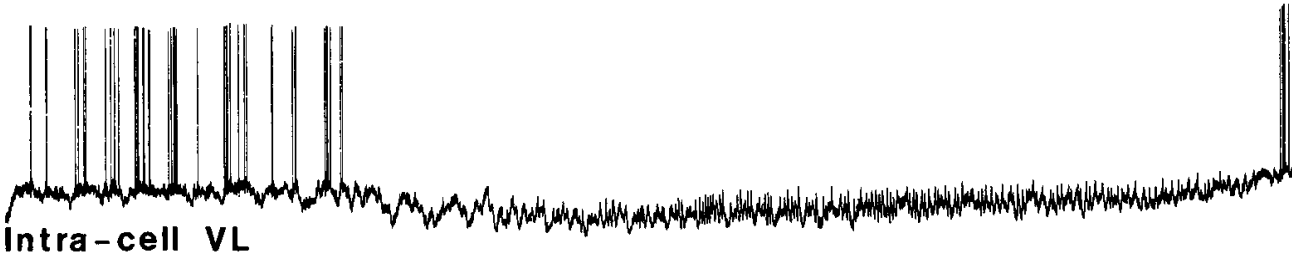

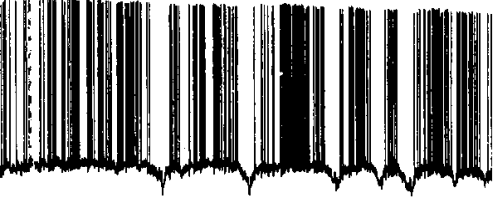

$-56 m v \quad$ B $\quad$ C

B

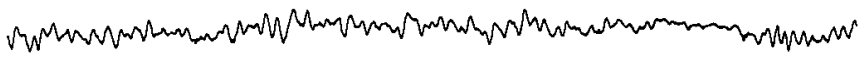
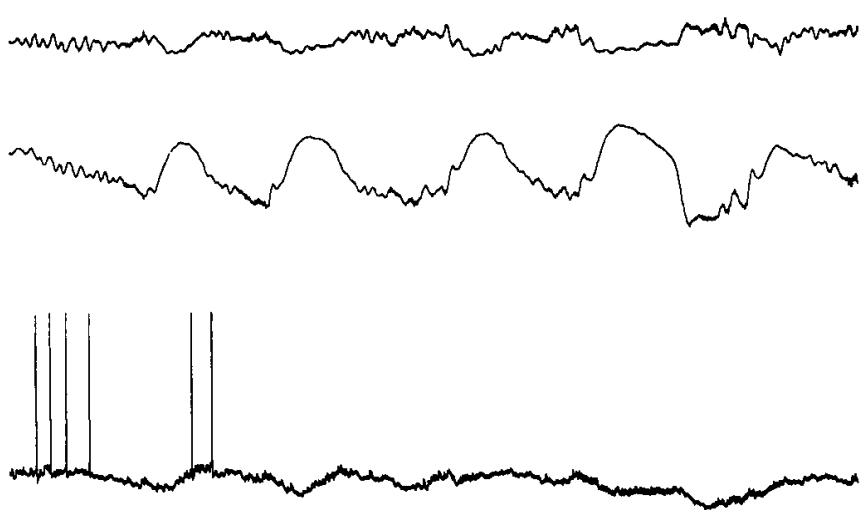

C

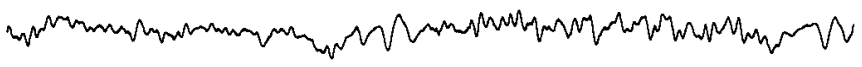

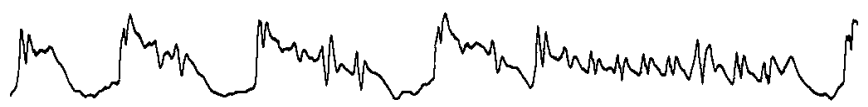

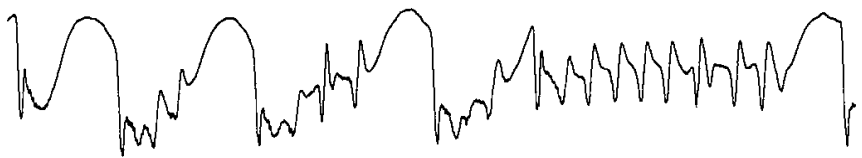

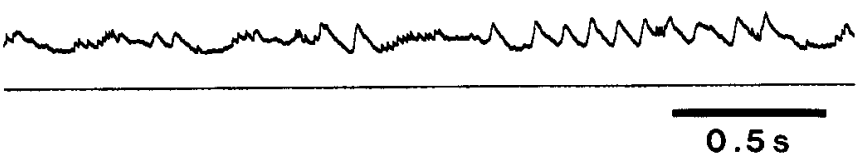

Figure 12. Hyperpolarization of TC neuron during SW seizure in related cortical area. $A$, Four traces depict simultaneously recorded EEG from the skull over the right area 4, surface and depth EEG from left area 4, and intracellular activity of TC neuron from left VL nucleus (bottom line is current monitor). Parts marked by $B$ and $C$ in $A$ are expanded below. The cortical paroxysm was initiated by progressively increased amplitudes of depth-positive EEG waves in left area 4 (see $B$ ) and was characterized by $\approx 2.5 \mathrm{~Hz} \mathrm{SW}$ complexes (left in $C$ ) alternating with activity at $\approx 10$ $\mathrm{Hz}$ (right in $C$ ). The VL cell was hyperpolarized from the very onset to the end of SW seizure. Note depolarization and increased firing rate of VL cell during the postseizure depression in area 4 and IPSPs related to depth-negative deflections in ipsilateral EEG.

Hz. The last traces in this sequential analysis represent the postictal activity. The superimposed expanded traces at right (taken from traces 28-33, and aligned on the same time zero represented by the peak depth negativity of the cortical EEG wave) show the IPSPs in the VL cell, following the excitatory events in the cortex by $\approx 20 \mathrm{msec}$.

\section{Discussion}

Two major findings resulted from these experiments. First, paroxysmal activities in corticothalamic networks developed progressively through increasing levels of neuronal synchronization during sleep EEG patterns. Second, while a subsample of TC cells were entrained by cortical $\mathrm{SW}$ activity and discharged spike bursts at $2-4 \mathrm{~Hz}$, an important proportion of TC cells $(60 \%)$ were hyperpolarized during the synchronous excitation of cortical and RE thalamic neurons throughout the SW seizure.

\section{Definition of paroxysmal episodes}

Paroxysmal episodes were defined here as epochs with distinct onset and end, in sharp contrast with the background activity, with increased amplitudes and altered frequencies of EEG waves leading to $2-4 \mathrm{~Hz}$ complexes and/or faster $(10-15 \mathrm{~Hz})$ rhythms, associated with corresponding patterns of neuronal activities 
A

A EEG area 4 - contra

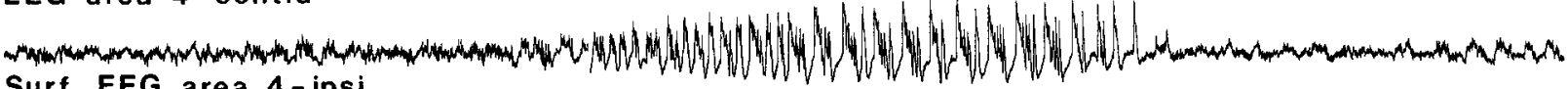
Surf. EEG area 4 -ipsi

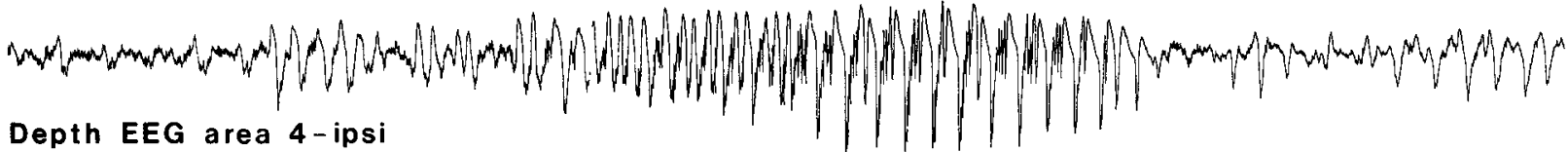

$\overline{\mathrm{B}}$

(C) intra-cell area 4

$-68 m V$

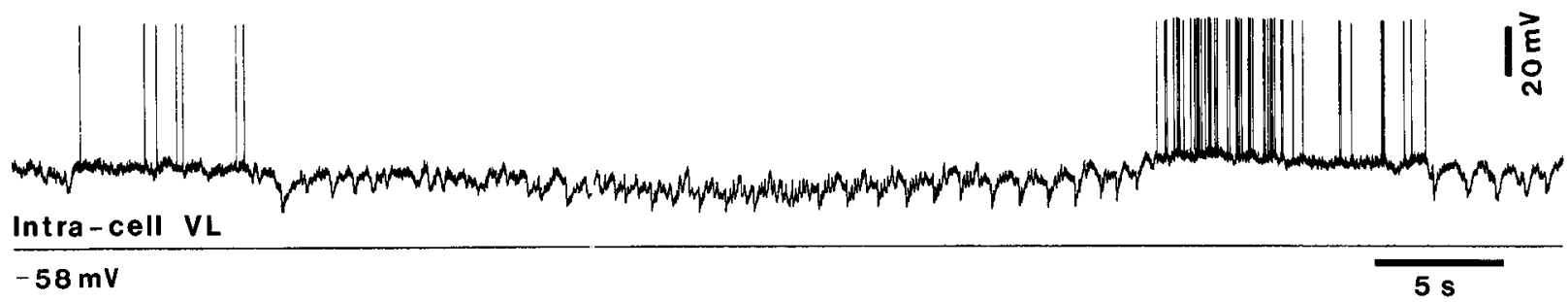

B

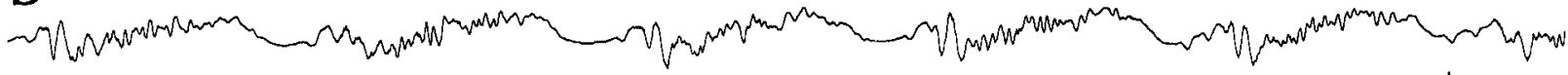

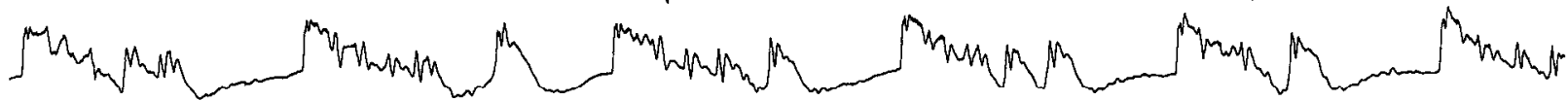

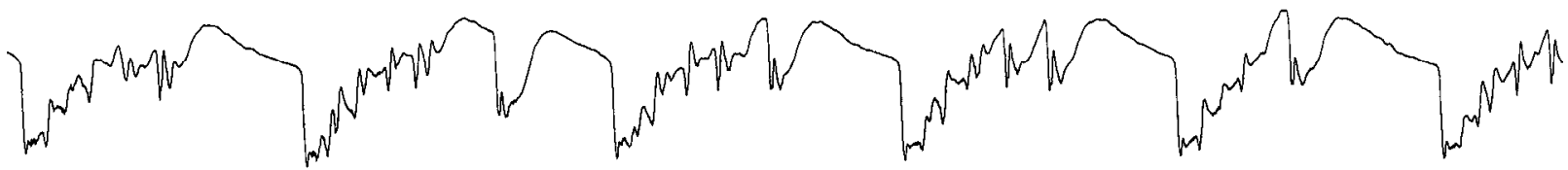
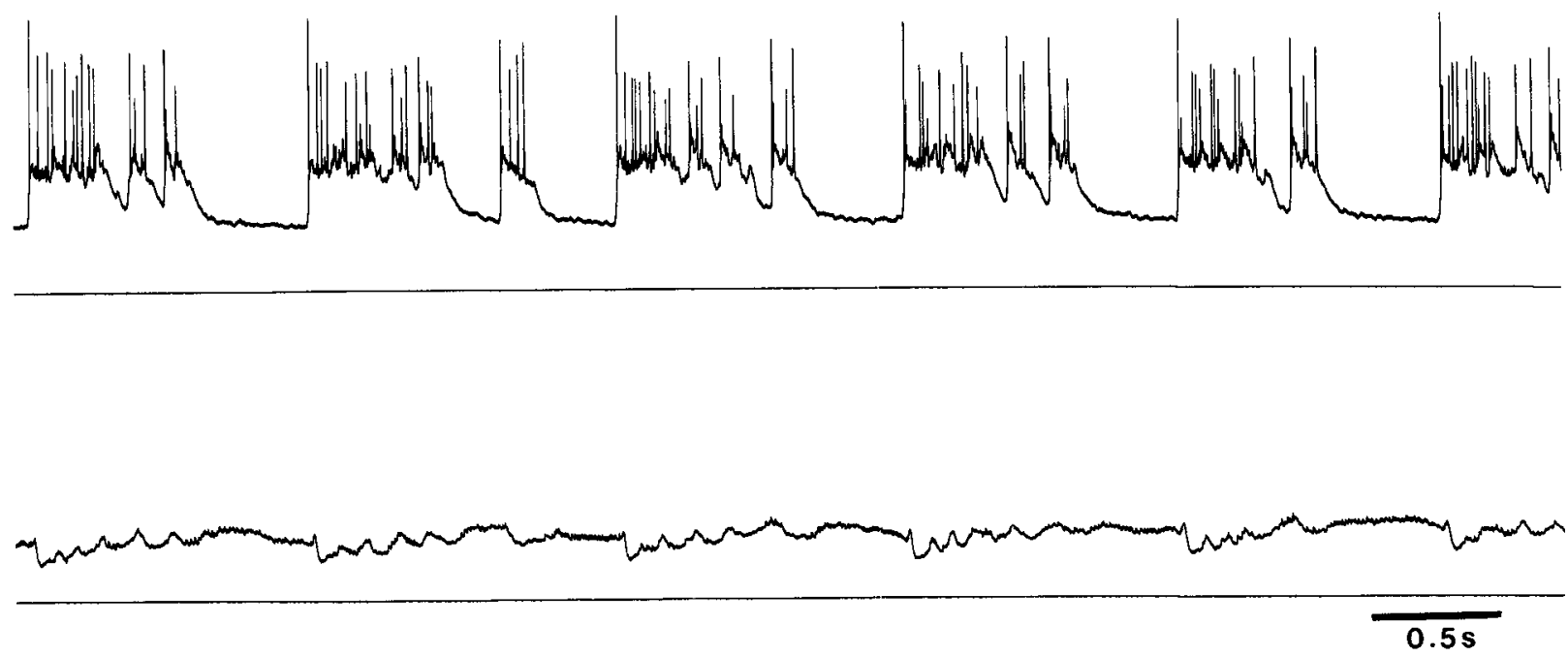

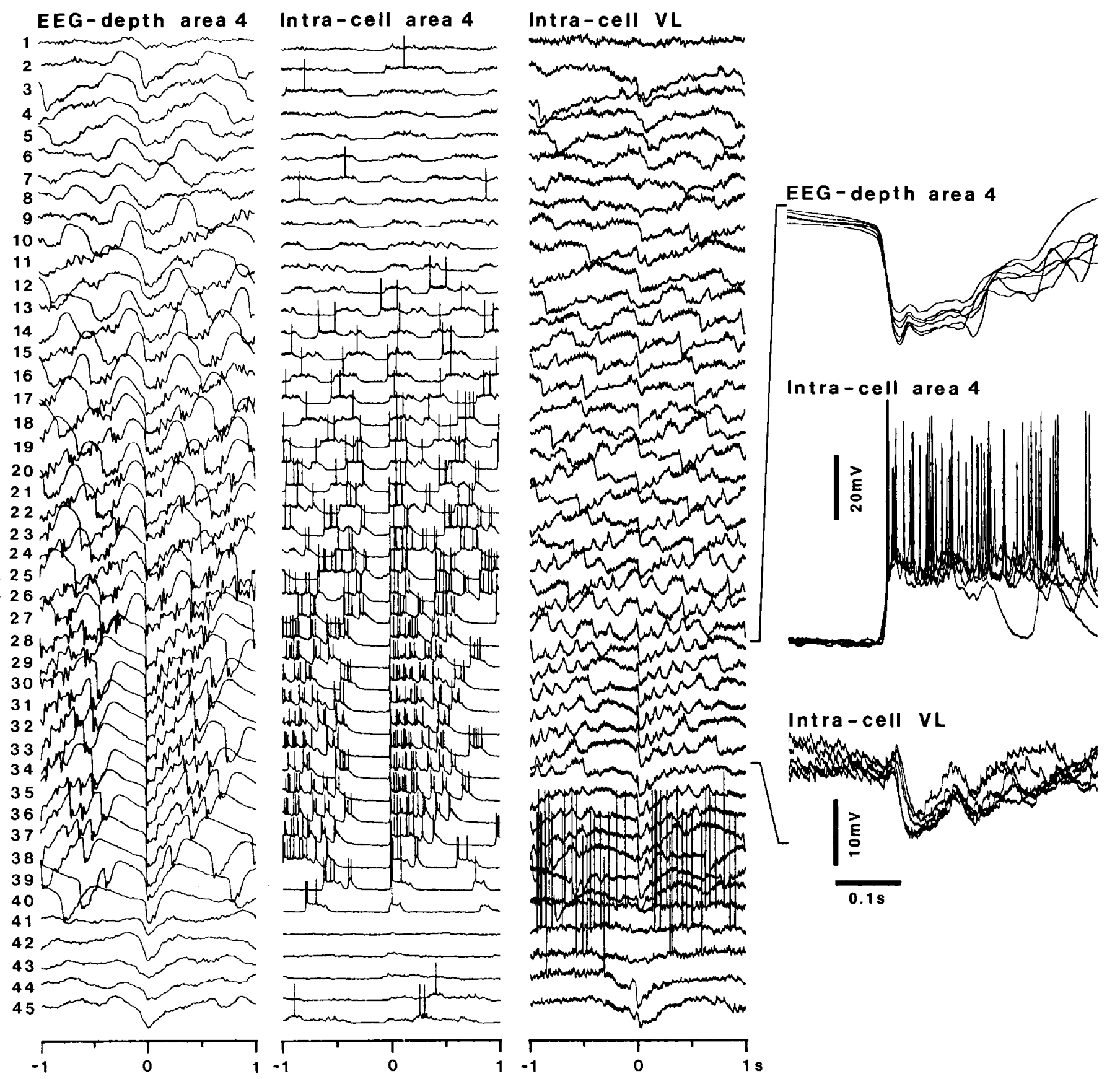

$1 \mathrm{~s}$

Figure 14. Corticothalamic relations during seizure. Dual intracellular recordings from area 4 and VL thalamic neurons. Three columns depict (left to right) simultaneously recorded EEG activity from depth of cortical area 4, intracellular activity in area 4 neuron, and intracellular activity in VL neuron. Sequential activities (to be read from top to bottom) were triggered by peak negativity of depth-cortical EEG (time zero). At right, superimposition of expanded six traces (from 28 to 33 in the columns at left). Voltage calibrations are different for area 4 and VL intracellular traces. See further details in text.

Figure 13. Dual intracellular recording demonstrating hyperpolarizations of VL TC cell during seizure depolarizations and spike bursts in area 4 cortical neuron. $A$, Five traces depict simultaneous recording of EEG from the skull over the right cortical area 4, surface and depth EEG from the left area 4 , and intracellular activities of area 4 cortical neuron and VL TC neuron (below each intracellular trace, current monitor). The seizure was initiated by a series of EEG waves at $\approx 0.9 \mathrm{~Hz}$ in the depth of left area 4 , continued with discharges at $\approx 2 \mathrm{~Hz}$, and ended with high-amplitude, periodic $(\approx 0.9 \mathrm{~Hz})$ EEG sequences consisting of $\approx 14 \mathrm{~Hz}$ wavelets. The latter are expanded in $B$. All these periods were faithfully reflected in the intracellular activity of cortical cell, whereas VL thalamic neuron displayed a tonic hyperpolarization throughout the seizure, with phasic sequences of IPSPs related to the large paroxysmal depolarizations and spike bursts occurring at the end of the seizure (see $B$ ). 
and an increase in the degree of synchronization between simultaneously recorded cortical and thalamic cells. Such spontaneously occurring episodes were observed in only $\approx 20 \%$ of experimental animals and cell groups. Although we observed this development into paroxysmal activity during ketamine and xylazine anesthesia, as similar events were not seen in the present series of experiments under other (urethane or barbiturate) anesthetic conditions, we could not determine other factors distinguishing the animals with or without paroxysmal propensity. Such factors, that remained uncontrolled in our study, may consist of genetic and sex differences between experimental animals (Marescaux et al., 1992; Jandó et al., 1994), unbalance between noradrenergic and other neuromodulatory systems (Noebels, 1984; Kostopoulos, 1992; Silva-Barrat et al., 1994), or hyposmolality increasing seizure susceptibility (Rosen and Andrew, 1990). That the occurrence of paroxysmal episodes is not dependent upon a given type of anesthesia, although ketamine and xylazine are particularly useful in studying synchronizing processes in corticothalamic networks (Contreras and Steriade, 1994), is shown by previous experiments in behaving or undrugged brainstem-transected animals in which typical SW seizures were elicited only in subsamples of recorded cortical neurons (Steriade, 1974; Steriade and Yossif, 1974). In those earlier experiments on nonanesthetized animals, the pattern of SW seizures (with spike bursts or spike trains in relation to the "spike" component, and silenced firing during the "wave") as well as their frequency $(2-4 \mathrm{~Hz})$ and duration $(10-15 \mathrm{sec})$ were similar to those reported in the present experiments. Despite all these electrographic resemblances to SW seizures in humans and behaving animals, absence epilepsy should remain a clinical notion. Our experiments were conducted on anesthetized and immobilized preparations to allow intracellular recordings in order to shed light on cellular mechanisms of electrographic patterns of SW seizures.

\section{Progressive development from sleep to seizure activity in corticothalamic networks}

That the cerebral cortex has the required neuronal machinery to develop self-sustained afterdischarges of the SW type in the absence of the thalamus was previously suggested by eliciting this pattern after stimulating the white matter underlying the primary somatosensory cortex in VP-lesioned preparations (Steriade and Yossif, 1974). Although in the intact brain the cortex and thalamus are together implicated in SW seizures (Avoli et al., 1983), the leading role of the cortex was proposed for either spontaneous seizures developing from spindle activity (Gloor et al., 1990) in the penicillin model (Prince and Farrell, 1963) or stimulus-induced SW afterdischarges (Steriade, 1974). However, the involvement of the thalamus insures a wide synchronization of normal and paroxysmal oscillations in view of the diffuse projections of RE nucleus to virtually all dorsal thalamic territories, whereas such a powerful device is seemingly absent in the cortex.

The present data support the view of a primary role played by the cerebral cortex by showing that sleep-like, normally synchronized EEG cortical patterns may develop into seizure activity, eventually reaching typical SW complexes at $2-4 \mathrm{~Hz}$. This transition may be achieved through at least two nonexclusive mechanisms. (1) The first one is a recruitment of cortical excitatory processes, as reflected in DC recordings by progressively enhanced amplitudes of depth-negative field potentials, well before any sign of overt thalamic entrainment (Fig. $1 B$ ).
Rhythmic $(\approx 3 \mathrm{~Hz})$ inhibition occurred later on. In parallel experiments, we similarly observed that, during stimulus-induced SW seizures, cortical neurons display a tonic depolarization of 15-20 mV, sculptured by hyperpolarizing potentials at $2-4 \mathrm{~Hz}$ (Steriade and Amzica, 1994). (2) The second mechanism, initially consisting of long-lasting cortical inhibitory processes, is suggested by the appearance of prolonged depth-positive field potentials in the cortex, reliably followed by spike bursts in TC cells, and leading to a typical SW seizure during which the depthnegative spiky cortical component was time locked with TC cell spike bursts (Fig. 7A). That cortical events precede in many instances thalamic ones is also shown by the fact that, at a time when the cortical inhibitory wave developed, the IPSP of the TC neuron was not yet initiated (Fig. $6 C$, triangle preceding the $b$ curve).

In the preceding paper (Contreras and Steriade, 1994) we proposed that a general inhibitory mechanism underlies the synchronization of corticothalamic networks during low-frequency sleep rhythms. The basis of this assumption was the simultaneous occurrence of long-lasting periods of hyperpolarizations in cortical, RE, and TC cells, associated with prolonged depth-positive cortical EEG waves, marking the transitions toward states with increased synchronization. In all these cell types, a period of excitation (expressed by high-frequency rebound bursts in the case of thalamic cells) followed inhibitory periods within a narrow time window. The data in the present paper indicate that the sequence of neuronal events during SW seizures obeys the same rules as described during sleep-like patterns. The important role of inhibitory processes in the genesis of SW epilepsy was repeatedly emphasized (Pollen, 1964; Jasper, 1969; Steriade, 1974; Kostopoulos et al., 1983) by contrast to the reduction in inhibitory mechanisms during focal epileptogenesis (see Prince, 1993).

Besides the progressive evolution observed in cortical EEG activity, the smooth transition from sleep to seizure patterns was documented here by the progressive alteration in the duration of RE cell spike bursts, from the sleep period preceding the paroxysmal activity toward the initial and the subsequent part of the seizure (Fig. 4). The changing patterns in the burst activity of RE cells during different phases of transition from sleep to seizure indicated that, far from arising suddenly, the seizure was first associated with an increased duration of RE cell spike bursts (up to $200 \mathrm{msec}$ ), thereafter followed by their reduced duration and increase in frequency, occurring in parallel with the evolution of cortical paroxysmal activity (see the sequential evolution in Fig. $4 C$ ). When RE neurons were recorded simultaneously with TC cells, the latter displayed IPSPs at the same frequency as RE cell spike bursts (Fig. 5). Thus, the cortical inhibitory processes characterizing $\mathrm{SW}$ seizures are accompanied by inhibitory processes in TC neurons, presumably mediated by GABAergic RE neurons, and a shift in balance between fast and slow inhibitory mechanisms may be decisive in the transition from normal to paroxysmal SW seizure activity.

Anothcr indication of progrcssive changes from sleep to SW seizures was provided by investigating the temporal relations between the spike bursts of TC cells, demonstrating a continuous increase in the degree of synchronization. The progressive enhancement in the synchronization process, from the early part toward the end of SW seizures in TC cells (Fig. 8), the lagging of some thalamic cells, as well as the fact that thalamic paroxysmal activity may outlast the cortical seizures (Fig. $1 B$ ), support the data indicating that the paroxysmal activity is trav- 
eling through intracortical and corticothalamic networks (Steriade and Amzica, 1994).

\section{Hyperpolarization of thalamocortical cells during $S W$ seizures}

Probably the most surprising set of results relates to the hyperpolarization of a TC neuronal population during the tempestuous, rhythmic excitatory-inhibitory sequences in cortical neurons during the SW paroxysms. To date, all available data point to the resonant activity of TC neurons during seizures, as these cells are usually thought of as giving rise to spike bursts at the same frequency as that displayed by cortical neurons. This aspect was also revealed in a subsample of TC neurons recorded in the present experiments (see Figs. 7-10) and suggests that the high-frequency bursts of some TC cells may reinforce the cortical seizure. I Iowever, an even higher number of TC cells remained tonically hyperpolarized during the cortical SW seizure and were phasically inhibited during each paroxysmal depolarizing event in the simultaneously recorded cortical cell, without discharging any action potential throughout the seizure (Figs. 12-14). This may seem contradictory to the notion that TC spike bursts close the loop of reciprocal projections between the cortex and thalamus and, thus, contribute to full synchronization of corticothalamic network.

Recent data indicate that RE neuron and TC cell inhibition has a decisive role in SW seizures at pure $2-4 \mathrm{~Hz}$ frequencies. Indeed, the blockage of the low-threshold $\mathrm{Ca}^{2+}$ conductance by injections of $\mathrm{Cd}^{2+}$ within the $\mathrm{RE}$ nucleus leads to a decrease in the ipsilateral SW epileptic activity (Avanzini et al., 1992). Also, excitotoxic lesions of RE cells led to abolition of ipsilateral SW discharges (Avanzini et al., 1993). At the dorsal thalamic level, injections of $\mathrm{GABA}_{\mathrm{B}}$ agonists enhance $S W$ activity in rats with genetic absence epilepsy, whereas $\mathrm{GABA}_{\mathrm{B}}$ antagonists reduce the incidence of these seizures (Liu et al., 1992). The role of $\mathrm{GABA}_{\mathrm{B}}$-mediated responses in providing a timing mechanism for promoting intrathalamic oscillations at $2-4 \mathrm{~Hz}$ was recently studied in vitro (von Krosigk et al., 1993; Huguenard and Prince, 1994).

Our data suggest that in at least one population of TC cells, SW seizures are expressed as rhythmic IPSPs over a background of a steady hyperpolarization, without succeeding in de-inactivating the transient low-threshold conductance underlying highfrequency spike bursts (Figs. 13, 14). In some cases, this failure of TC cells to display bursting firing may be ascribed to the fact that they displayed IPSPs at the spindle frequency $(8-10 \mathrm{~Hz})$, higher than that of SW complexes, in parallel with a similar rhythm of cortical discharges (see Fig. 14). It is known that TC cclls do not discharge on every intraspindle cycle (Roy et al., 1984; Steriade et al., 1985; von Krosigk et al., 1993) or even at all during a spindle sequence (Steriade and Llinás, 1988), probably because $T$ channels are incompletely de-inactivated. However, in other instances TC cells displayed IPSPs at the typical frequency of SW seizures, in close time relation with RE cell spike bursts, and still they did not burst (Fig. $4 B$ ). In such cases, when the $V_{m}$ was steadily and progressively hyperpolarized during the seizure (see also Figs. 12,13), we have to consider that the summated action of RE neurons, which were able to discharge exceedingly long spike bursts at every SW cycle (Figs. 4, 5), rendered TC neurons in a state that prevented their discharges.

The influence of the cerebral cortex may be differentially exerted on various pools of TC neurons, depending on the degree of feedforward inhibition mediated by RE cells. By contrast to sensory nuclei, other dorsal thalamic territories are innervated by more than one RE district. This is not only the case of rostral intralaminar nuclei, but also of the VL nucleus where most of our experiments were performed and that receives afferents from the rostral pole as well as the lateral peri-VL zone of the RE nuclear complex (Steriade et al., 1984). This may account for a higher degree of convergence upon TC cells and a higher frequency of IPSPs. Also, different seizure episodes may reflect varying degrees of balance between cortical excitatory and $R E$ inhibitory influences upon TC cells. We propose that paroxysmal activities in the corticothalamic circuitry are expressed within a range of frequencies and combinations between excitatory and inhibitory influences that would go beyond the usual classifications.

\section{Final remarks}

These results pertain to the mechanisms of pathophysiological oscillations in corticothalamic networks, some of them with discharge patterns almost indistinguishable from SW seizures at $\approx 3 \mathrm{~Hz}$. At variance to other models of experimental epilepsy, in which various drugs and receptor blockers are administered, our data were oblained in a preparation with preserved connections and intact network operations, thus allowing the study of dynamic relations among cortical, RE, and TC cells, the major elements involved in the genesis of normal and epileptic brain oscillatory activity, in a brain fluctuating from sleep to paroxysmal activity patterns. Together with the data presented in the preceding paper, these results point to the similarity between the phase relations between cortical and thalamic neurons during sleep and transition toward a hypersynchronous, epilepticlike state. We suggest that a principal factor responsible for the unconsciousness characterizing the SW seizures is the dramatic inhibition of TC cells and their incapacity of relaying messages from the outside world.

\section{References}

Avanzini G, De Curtis M, Marescaux C, Panzica F, Spreafico R, Vergnes $M$ (1992) Role of the thalamic reticular nucleus in the generation of rhythmic thalamo-cortical activities subserving spike and waves. J Neural Transm [Suppl] 35:85-95.

Avanzini G, Vergnes M, Spreafico R, Marescaux C (1993) Calciumdependent regulation of genetically determined spike and waves by the reticular thalamic nucleus of rats. Epilepsia 34: I-8.

Avoli M, Gloor P, Kostopoulos G, Gotman J (1983) An analysis of penicillin-induced generalized spike and wave discharges using simultaneous recordings of cortical and thalamic single neurons. J Neurophysiol 50:819-837.

Contreras D, Steriade M (1995) Cellular basis of EEG slow rhythms: a study of dynamic corticothalamic relationships. J Neurosci 15:604 622.

Contreras D, Curró Dossi R, Steriade M (1993) Electrophysiological properties of cat reticular thalamic neurones in vivo.. J Physiol (Lond) 470:273-294.

Domich L, Oakson G, Steriade M (1986) Thalamic burst patterns in the naturally sleeping cat: a comparison between cortically projecting and reticularis neurones. J Physiol (Lond) 379:429-449.

Gloor P, Fariello RG (1988) Generalized epilepsy: some of its cellular mechanisms differ from those of focal epilepsy. Trends Neurosci 11: 63-68.

Gloor P, Avoli M, Kostopoulos G (1990) Thalamocortical relationships in generalized epilepsy with bilaterally synchronous spike-andwave discharge. In: Generalized epilepsy (Avoli M, Gloor P, Kostopoulos G, Naquet R, eds), pp 190-212. Boston: Birkhäuser.

Huguenard JR, Prince DA (1992) A novel T-type current underlies prolonged $\mathrm{Ca}^{2+}$-dependent burst firing in GABAergic neurons of rat thalamic reticular nucleus. J Neurosci 12:3804-3817.

Huguenard JR, Prince DA (1994) Intrathalamic rhythmicity studied 
in vitro: nominal $\mathrm{T}$ current modulation causes robust anti-oscillatory effects. J Neurosci 14:5485-5502.

Jandó G, Carpi D, Kandel A, Urioste R, Horvath Z, Pierre E, Vati D, Vadasz C, Buzsáki G (1994) Spike-and-wave epilepsy in rats: sex differences and inheritance of physiological traits. Neuroscience, in press.

Jasper HH (1969) Mechanism of propagation: extracellular studies. In: Basic mechanisms of the epilepsies (Jasper HH, ed), pp $421-438$. Boston: Little, Brown.

Jones EG (1985) The thalamus. New York: Plenum

Kellaway P (1985) Sleep and epilepsy. Epilepsia [Suppl 1] 26:15-30.

Kostopoulous GK (1992) The tottering mouse: a critical review of its usefulness in the study of the neuronal mechanisms underlying epilepsy. J Neural Transm [Suppl] 35:21-36.

Kostopoulos G, Avoli M, Gloor P (1983) Participation of cortical recurrent inhibition in the genesis of spike and wave discharges in feline generalized penicillin epilepsy. Brain Res 267:101-112.

Leresche N, Lightowler S, Soltesz I, Jassik-Gerschenfeld D, Crunelli V (1991) Low-frequency oscillatory activities intrinsic to rat and cat thalamocortical cells. J Physiol (Lond) 441:155-174.

Liu Z, Vergenes M, Depaulis A, Marescaux C (1992) Involvement of intrathalamic $\mathrm{GABA}_{\mathrm{B}}$ neurotransmission in the control of absence seizures in the rat. Neuroscience 48:87-93.

Marescaux C, Vergnes M, Depaulis A (1992) Genetic absence epilepsy in rats from Strasbourg-a review. J Neural Transm [Suppl] 35:3769.

McCormick DA, Pape HC (1990a) Properties of a hyperpolarizationactivated cation current and its role in rhythmic oscillation in thalamic relay neurones. J Physiol (Lond) 431:291-318.

Noebels JL (1984) A single error of noradrenergic axon growth synchronizes central neurons. Nature 310:409-411.

Nuñez A, Curró Dossi R, Contreras D, Steriade M (1992) Intracellular evidence for incompatibility between spindle and delta oscillations in thalamocortical neurons of cat. Neuroscience 48:75-85.

Pollen DA (1964) Intracellular studies of cortical neurons during thalamic induced wave and spike. Electroencephalogr Clin Neurophysiol 17:398-404.

Prince DA (1993) Basic mechanisms of focal epileptogenesis. In: Epileptogenic and excitotoxic mechanisms (Avanzini G, Fariello R, Heinemann U, Mutani R, eds), pp 17-27. London: Libbey.

Prince DA, Farrell D (1963) "Centrencephalic" spike-wave discharges following parenteral penicillin injection in the cat. Neurology 19:309310.

Rosen AS, Andrew RD (1990) Osmotic effects upon excitability in rat neocortical slices. Neuroscience 38:579-590.

Roy JP, Clercq M, Steriade M, Deschênes M (1984) Electrophysiology of neurons of the lateral thalamic nuclei in cat: mechanisms of longlasting hyperpolarizations. J Neurophysiol 51:1220-1235.

Silva-Barrat C, Champagnat J, Leiva J, Pavlik V (1994) Noradrenaline mediates paradoxical effects on rat neocortical neurons after GABA withdrawal. J Neurophysiol 71:1139-1150.

Soltesz I, Lightowler S, Leresche N, Jassik-Gerschenfeld D, Pollard CE, Crunelli V (1991) Two inward currents and the transformation of low-frequency oscillations of rat and cat thalamocortical cells. J Physiol (Lond) 441:175-197.

Steriade M (1964) Development of evoked responses into self-sus- tained activity within amygdalo-hippocampal circuits. Electroencephalogr Clin Neurophysiol 16:221-236.

Steriade M (1974) Interneuronal epileptic discharges related to spikeand-wave cortical seizures in behaving monkeys. Electroencephalogr Clin Neurophysiol 37:247-263.

Steriade M (1990) Spindling, incremental thalamocortical responses, and spike-wave epilepsy. In: Generalized epilepsy (Avoli M, Gloor P, Kostopoulos G, Naquet R, eds), pp 161-180. Boston: Birkhäuser.

Steriade M, Amzica F (1994) Dynamic synaptic coupling among neocortical neurons during evoked and spontaneous spike-wave seizure activity. J Neurophysiol 72:2051-2069.

Stcriade M, Llinás RR (1988) The functional states of the thalamus and the associated neuronal interplay. Physiol Rev 68:649-742.

Steriade M, YossifG (1974) Spike-and-wave afterdischarges in cortical somatosensory neurons of cat. Electroencephalogr Clin Neurophysiol 37:633-648.

Steriade M, Wyzinski P, Apostol V (1972) Corticofugal projections governing rhythmic thalamic activity. In: Corticothalamic projections and sensorimotor activities (Frigyesi TL, Rinvik E, Yahr MD, eds), pp 221-272. New York: Raven.

Steriade M, Oakson G, Diallo A (1976) Cortically elicited spike-wave afterdischarges in thalamic neurons. Electroencephalogr Clin Neurophysiol 41:641-644.

Steriade M, Parent A, Hada J (1984) Thalamic projections of nucleus reticularis thalami of cat: a study using retrograde transport of horseradish peroxidase and fluorescent tracers. J Comp Neurol 229:531547.

Steriade M, Deschênes M, Domich L, Mulle C (1985) Abolition of spindle oscillations in thalamic neurons disconnected from nucleus reticularis thalami. J Neurophysiol 54:1473-1497.

Steriade M, Domich L, Oakson G (1986) Reticularis thalamic neurons revisited: activity changes during shifts in states of vigilance. J Neurosci 6:68-81.

Steriade M, Domich L, Oakson G, Deschênes M (1987) The deafferented reticularis thalami nucleus generates spindle rhythmicity. $J$ Neurophysiol 57:260-273.

Steriade M, Curró Dossi R, Nuñez A (1991) Network modulation of a slow intrinsic oscillation of cat thalamocortical neurons implicated in sleep delta waves: cortically induced synchronization and brainstcm cholinergic suppression. J Neurosci 11:3200-3217.

Steriade M, Nuñez A, Amzica F (1993a) A novel slow $(<1 \mathrm{~Hz})$ oscillation of neocortical neurons in vivo: depolarizing and hyperpolarizing components. J Neurosci 13:3252-3265.

Steriade M, Nuñez A, Amzica F (1993b) Intracellular analysis of relations between the slow $(<1 \mathrm{~Hz})$ neocortical oscillation and other sleep rhythms of the electroencephalogram. J Neurosci 13:3266-3283.

Steriade M, Contreras D, Curró Dossi R, Nuñez A (1993c) The slow $(<1 \mathrm{~Hz})$ oscillation in reticular thalamic and thalamocortical neurons: scenario of sleep rhythm generation in interacting thalamic and neocortical networks. J Neurosci 13:3284-3299.

Von Krosigk M, Bal T, McCormick DA (1993) Cellular mechanisms of a synchronized oscillation in the thalamus. Science 261:361-364.

Waszak M (1974) Firing pattern of neurons in the rostral and ventral part of nucleus reticularis thalami during EEG spindles. Exp Neurol 43:38-59. 